\title{
Late miocene to late pleistocene geomagnetic secular variation at high-northern latitudes
}

Døssing, Arne; Riishuus, Morten S.; Niocaill, Conall Mac; Muxworthy, Adrian R; MacLennan, John

Published in:

Geophysical Journal International

Link to article, DOI:

10.1093/gji/ggaa148

Publication date:

2020

Document Version

Publisher's PDF, also known as Version of record

Link back to DTU Orbit

Citation (APA):

Døssing, A., Riishuus, M. S., Niocaill, C. M., Muxworthy, A. R., \& MacLennan, J. (2020). Late miocene to late pleistocene geomagnetic secular variation at high-northern latitudes. Geophysical Journal International, 222(1), 86-102. https://doi.org/10.1093/gji/ggaa148

\section{General rights}

Copyright and moral rights for the publications made accessible in the public portal are retained by the authors and/or other copyright owners and it is a condition of accessing publications that users recognise and abide by the legal requirements associated with these rights.

- Users may download and print one copy of any publication from the public portal for the purpose of private study or research.

- You may not further distribute the material or use it for any profit-making activity or commercial gain

- You may freely distribute the URL identifying the publication in the public portal 


\title{
Late Miocene to late Pleistocene geomagnetic secular variation at high northern latitudes
}

\author{
Arne Døssing, ${ }^{1}$ Morten S. Riishuus, ${ }^{2}$ Conall Mac Niocaill, ${ }^{3}$ \\ Adrian R. Muxworthy ${ }^{\oplus 4}$ and John Maclennan ${ }^{5}$ \\ ${ }^{1}$ CMAGTRES, DTU Space, Technical University of Denmark, Centrifugevej 356, 2800 Kgs. Lyngby, Denmark. E-mail: ards@space.dtu.dk \\ ${ }^{2}$ Jardfeingi-The Faroese Geological Survey, Jóannesar Paturssonargøta 32-34, FO-110 Tórshavn, Faroe Islands \\ ${ }^{3}$ Department of Earth Sciences, University of Oxford, S Parks Rd, Oxford OX13AN, UK \\ ${ }^{4}$ Department of Earth Science and Engineering, Imperial College London, South Kensington Campus, London SW72AZ, UK \\ ${ }^{5}$ Department of Earth Sciences, University of Cambridge, Downing Street - S403, Cambridge, Cambridgeshire CB23EQ, UK
}

Accepted 2020 March 17. Received 2020 March 10; in original form 2019 November 23

\begin{abstract}
SUMMAR Y
We report a palaeomagnetic study of Icelandic lavas of late Miocene to late Pliocene age to test the geocentric axial dipole hypothesis at high northern latitudes. Cores were sampled from 125 sites in the Fljótsdalur valley in eastern Iceland, and hand samples were taken for 17 new incremental heating ${ }^{40} \mathrm{Ar} /{ }^{39} \mathrm{Ar}$ age determinations. 96 per cent of the cores were oriented using both a Brunton compass and a sun compass. Comparison of the magnetic and sun azimuths reveals deviations of $\pm 5^{\circ}, \pm 10^{\circ}$ and $\pm 20^{\circ}$, respectively, for 42,16 and 3 per cent of the data points, indicating that core sampling intended for palaeosecular variation (PSV) studies at high northern latitudes should be oriented by sun. A total of 1279 independent specimens were subjected to AF- and thermal-demagnetization for palaeodirectional analysis, and wellgrouped site mean directions were obtained for 123 sites of which 113 were found to be independent sites. Applying a selection criteria of $k>50$ and $N \geq 5\left(N_{\text {mean }}=9.5\right)$, we obtain a combined grand mean direction for 46 normal and 53 reverse (for $\mathrm{VGP}_{\text {lat }}> \pm 45^{\circ}$ ) polarity sites of declination $=5.6^{\circ}$ and inclination $=77.5^{\circ}$ that is not significantly different from that expected from a GAD field. The corresponding palaeomagnetic pole position $\left(\mathrm{VGP}_{\text {lat }}=\right.$ $86.3^{\circ} \mathrm{N}, \mathrm{VGP}_{\text {lon }}=21.2^{\circ} \mathrm{E}, \mathrm{d} p / \mathrm{d} m=4.0^{\circ} / 4.3^{\circ}$ ) is coincident with the North Pole within the 95 per cent confidence limits. An updated age model is constructed based on the ${ }^{40} \mathrm{Ar} /{ }^{39} \mathrm{Ar}$ ages, showing that the majority of the Fljótsdalur lavas fall within 2-7 Ma. We combine the Fljótsdalur data with existing data from the nearby Jökuldalur valley. The 154 palaeodirections are well-dispersed between 1 and $7 \mathrm{Ma}$ and constitute a high-quality data set for PSV analysis. Our results partly support previous conclusions of a generally higher dispersion during reverse polarity intervals. However, when comparing our Matutayma data with Brunhes age data from Jan Mayen, we find no evidence of a higher VGP scatter during the Matuyama as previously suggested. When comparing our VGP scatter to the two commonly used models for VGP dispersion: Model G and TK03, we find a good fit for all 1-7 Ma VGP scatter data $S_{B(1-7)}$ to Model G, whereas $S_{B(1-7)}$ is not fitted by TK03, even when considering the uncertainty of $S_{B(1-7)}$. We also find that all VGP scatter estimates, except that for the Gilbert subset, are consistent with Model G, while the discrepancy with TK03 is generally larger.
\end{abstract}

Key words: Thermochronology; Arctic region; Palaeomagnetic secular variation; Palaeomagnetism; Reversals: process, time scale, magnetostratigraphy.

\section{INTRODUCTION}

Satellite and ground observatory observations of the Earth's magnetic field (the geomagnetic field) show that it changes over time in both direction and intensity. These temporal changes are known as secular variation and are thought to reflect both short- and longterm changes in fluid processes in the Earth's core (Johnson \& McFadden 2007). A fundamental assumption of palaeomagnetism that the secular variation when observed at geological timescales, that is, palaeosecular variation (PSV), is averaged out and the 
time-averaged geomagnetic field (TAF) is a geocentric axial dipole field: this hypothesis is known as the geocentric axial dipole (GAD) hypothesis (Hospers 1954). However, the question remains as to how long must the Earth's field be averaged to be a GAD (Lawrence et al. 2009; Aubert et al. 2010; Tauxe 2010; Korte et al. 2011; Cromwell et al. 2013, 2018; Pavón-Carrasco et al. 2014; Ziegler \& Constable 2015).

By examining the temporal and spatial variations in the Earth's magnetic field over time using palaeomagnetic data, we may be able to test the validity of the GAD hypothesis. However, in order to conduct sound statistical studies of the TAF and PSV, we need global palaeomagnetic databases that are unbiased in terms of the temporal and spatial sampling for the period investigated with data being of high quality (Johnson et al. 2008).

In order to conduct statistical studies of the TAF and PSV, it has been argued that an ideal data set would sample the geomagnetic field on the order of $10^{6}$ years from about 100-200 sites (Ziegler et al. 2011; Lhuillier \& Gilder 2013). Cromwell et al. (2018) have further considered the minimum number of ChRMs per site needed to confidently trust individual palaeodirections as input for TAF and PSV studies. They suggest a data selection criteria with $N \geq$ 4 (minimum number of ChRMs per site) and $k \geq 50$. This cut-off is based on simulations by Cromwell et al. (2018) that indicate that within-site estimates of the circular standard deviation $\left(c_{w}\right)$ is reduced by $\sim 35$ percent for $N=4$ as compared to $N=2$. Interestingly, the same study shows that the variance of $c_{w}$ is reduced by further $\sim 27$ per cent for $N=10$ as compared to $N=4$, while an improvement of only $\sim 7$ percent is obtained for $N=15$ as compared to $N=10$. This suggests that it is worthwhile obtaining data sets with $N=10$,

Early attempts to compile palaeomagnetic global data sets for modelling the PSV and TAF over geological timescales of $10^{5}$ $10^{6} \mathrm{yr}$ indicated that many of the older palaeomagnetic results are of too low quality to truly test the GAD hypothesis (Johnson \& Constable 1997). Modern palaeomagnetic data sets with relatively strict data standards have since then been collected and used as input for global palaeomagnetic databases to model, for example, the 0 $5 \mathrm{Ma}$ geomagnetic field (Johnson et al. 2008) and recently also the 0-10 Ma field (Cromwell et al. 2018). However, considerable temporal and geographical biases remain in the databases with a majority of data points being less than $500 \mathrm{kyr}$ old and collected at low- to mid-latitudes (Johnson et al. 2008; Cromwell et al. 2018).

The basaltic lava piles of the Iceland plateau, exposed onshore in deeply dissected valley and fjord systems $\left(64-66^{\circ} \mathrm{N}\right)$, are well suited for palaeomagnetic studies due to their fidelity at recording primary remanent magnetizations, the large number of accessible flows with minimal hydrothermal alteration covering the past 15 $16 \mathrm{Myr}$ (Hardarson et al. 1997), and the limited post-emplacement tectonic disturbance (Kristjánsson \& Jonsson 2007). Despite a large collection of palaeomagnetic studies over the past 50-60 years (McDougall et al. 1977; Watkins \& Walker 1977; Kristjánsson \& Jóhannesson 1999; Kristjansson 2013), only few studies report TAF and PSV behaviour for rocks older than 0.5 Ma using modernstandard quality criteria (Johnson et al. 2008; Cromwell et al. 2018). Instead, a large majority of the studies focus on either transitional polarity events and excursions or on detailed magnetostratigraphic correlations (Dagley et al. 1967; Watkins \& Walker 1977; Kristjánsson 2008; Camps et al. 2011; Jicha et al. 2011), with the latter studies mostly being based on two samples per flow. A compilation study of 0-16 Ma Icelandic lavas was presented by Kristjansson (2013), covering remanence results of more than 5200 lava flows that were collected over the past 50 years. Despite that the majority of the studies are based on two samples per site, an interesting outcome of the study is an apparently smooth and continuous frequency distribution of Icelandic virtual geomagnetic poles (VGPs) in latitude, suggesting that secular variation, excursions and transitions could be treated jointly in VGP statistical studies as manifestations of turbulent convective processes in the Earth's core.

In 2013 and 2014, we visited the large Fljótsdalur valley in eastern Iceland (Fig. 1) with the purpose of providing high-quality palaeodirectional, palaeointensity and ${ }^{40} \mathrm{Ar} /{ }^{39} \mathrm{Ar}$ data for the late Miocene to late Pliocene period from high northern latitudes. The valley was originally sampled by Dagley et al. (1967) and Watkins \& Walker (1977), collecting two cores per site. In total, we sampled 125 sites along five sections in Fljótsdalur as part of an eight weeks sampling campaign that also included sampling of late Pliocene-Pleistocene rocks in the neighbouring Jökuldalur valley (Fig. 1). Palaeodirectional and palaeointensity data from 45 distinct lavas flows, including 11 new ${ }^{40} \mathrm{Ar} /{ }^{39} \mathrm{Ar}$ ages, were published from Jökuldalur (Døssing et al. 2016).

Here, we present an analysis of the palaeodirectional data from Fljótsdalur, including a revised age model of the lava flows in the valley based on 17 new ${ }^{40} \mathrm{Ar} /{ }^{39} \mathrm{Ar}$ age determinations. The age of the lavas in Fljótsdalur allows us to combine the results in this study with the results of Jökuldalur in order to construct an estimate of the PSV for high northern latitudes for the late Miocene to Pleistocene. Hence, we present high-quality estimates of PSV for the 1-7 Ma time interval by making a joint analysis of the Fljótsdalur and Jökuldalur palaeodirectional data.

\section{GEOLOGY AND PREVIOUS WORK}

Iceland is located in the Northeast Atlantic at $63-67^{\circ} \mathrm{N}$. The island itself sits at the junction between the North Atlantic Ridge and the Greenland-Iceland-Faroe Islands ridge and atop anomalously hot mantle. In this unique extensional tectonic setting, the active volcanic rift zones (see inset map in Fig. 1), that is, the northern volcanic zone (NVZ), the eastern volcanic zone (EVZ) and the western volcanic zone (WVZ), are infilled with basaltic extrusive and intrusive rocks. During this progressive accumulation of volcanic material the areas around the volcanic zones cool, contract and subside continuously, causing the lava sequences to tilt gently towards the axes of the volcanic zones (Pálmason \& Sæmundsson 1974).

The southwest-northeast striking Fljótsdalur valley is located on the Eurasian Plate in eastern Iceland, about $80 \mathrm{~km}$ east of the NVZ (Fig. 1). A comprehensive geological mapping of the valley was carried out in the late 1970s as part of an M.Sc. project by Gudmundsson (1978). However, the first palaeomagnetic campaign in Fljótsdalur, collecting two cores per site, was already conducted in 1964 and 1965 as part of a large sampling campaign that focused on regional magnetostratigraphic correlation across eastern Iceland (Dagley et al. 1967; Watkins \& Walker 1977). Based on this regional stratigraphic framework, Dagley et al. (1967) and Watkins \& Walker (1977) suggested that the lavas in the upper southwestern part of Fljótsdalur, that is, along sections FR to FV, are of late Miocene to early Pleistocene age. This was later supported by six ${ }^{40} \mathrm{Ar} /{ }^{39} \mathrm{Ar}$ ages (Mussett et al. 1980). Watkins \& Walker (1977) also found that the lava pile in eastern Iceland is characterized by an overall gently westerly dip and that the dip generally increases linearly with depth (and hence age) below the original surface. This conclusion was based on several hundred dip angle measurements of the lavas across eastern Iceland, including Fljótsdalur. 


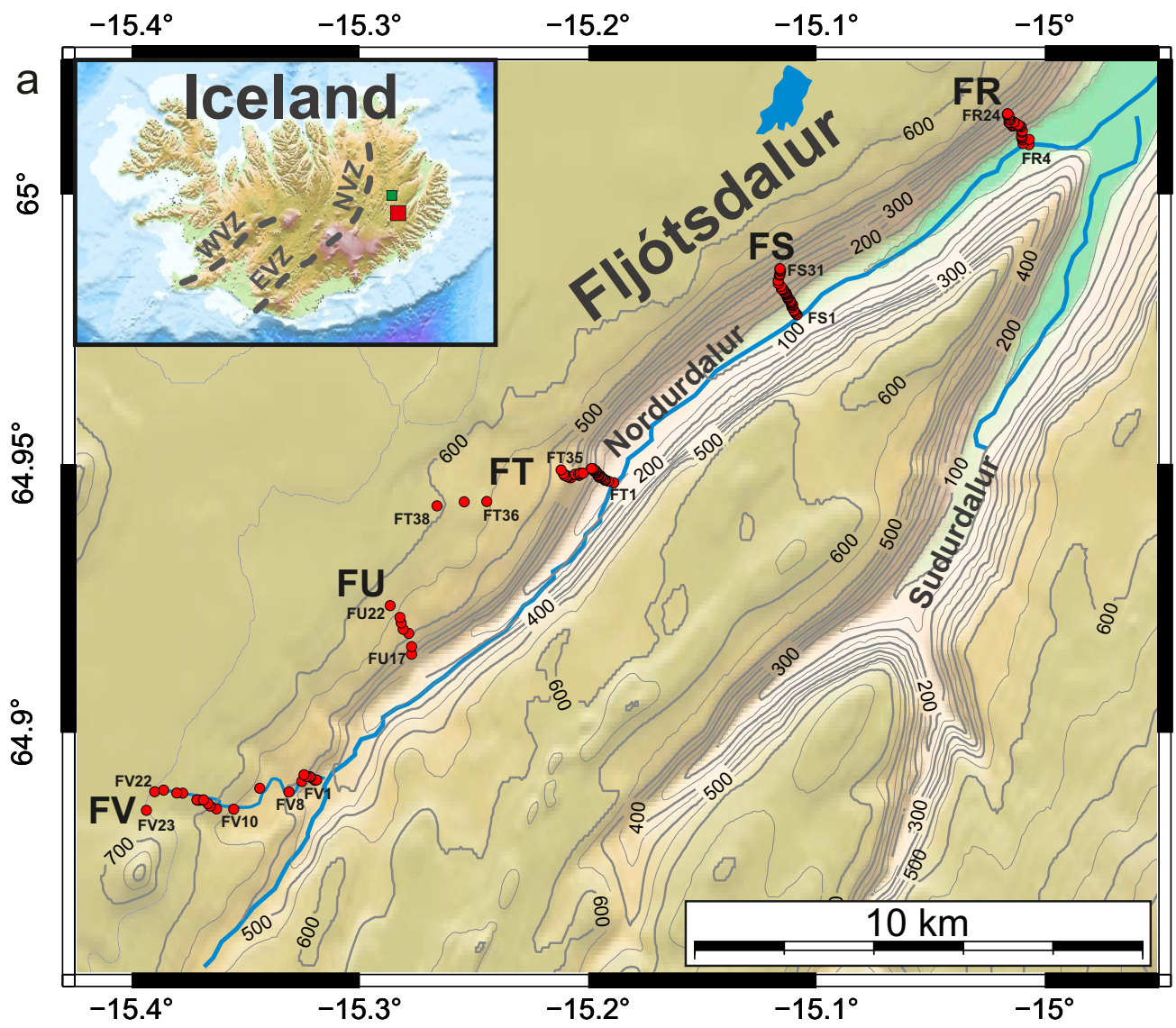

Figure 1. Topographic map of the upper part of the Fljótsdalur valley. 'Fljótsdalur' here refers to the main tributary valley Nordurdalur. Red dots: Location of drilled sites along sections FR, FS, FT, FU and FV. Inset map of Iceland: red square, location of Fljótsdalur; green square: location of Jökuldalur where full-vector palaeomagnetic PSV results of 0.5-3.1 Ma rocks have recently been published (Døssing et al. 2016). Black dashed lines: main volcanic rift zones. Abbreviations: EVZ, eastern volcanic zone; NVZ, northern volcanic zone; WVZ, western volcanic zone.

In this study, we have revisited the basaltic lavas along sections FR to FV in Fljótsdalur. The five sections were initially mapped by Dagley et al. (1967) and Watkins \& Walker (1977), who named the five sections R, S, T, U and V. The lavas along the sections are ideal for PSV studies because they are well-mapped, easily accessible and exhibit a westerly dip less than $10^{\circ}$ (Watkins \& Walker 1977), because they are located outside a regional volcanic flexure zone to the northeast.

\section{METHODS}

\subsection{Core sampling}

We collected $>1500$ individual cores from 125 sites along sections FR, FS, FT, FU and FV (Figs 1 and 2) for palaeodirectional and palaeointensity analysis. The results of the palaeointensity analysis will be presented in a future study. Our core sampling was restricted to unaltered massive cores of basaltic lavas in well-defined flow units, and cores were preferably drilled over tens of metres to avoid the potential influence of lightning strikes and/or non in situ blocks. In compound flow units, we selected only one subunit for coring (e.g. FR8, FR19, FT11, FT17, etc.).

All cores were oriented using a Brunton magnetic compass. In addition, 96 per cent of all cores were oriented using a sun compass. This provides us with a unique data set for comparing magnetic and sun azimuths at high northern latitudes. As observed in Fig. 3, we find that 42,16 and 3 percent of the magnetic azimuth estimates (corrected to true north) deviate more than $\pm 5^{\circ}, \pm 10^{\circ}$ and $\pm 20^{\circ}$, respectively, from the corresponding sun azimuth estimates. These numbers strongly support the conclusion of Cromwell et al. (2013) that core sampling intended for high-quality PSV studies at high northern latitudes should preferably be oriented by sun (or alternatively by a differential GPS).

\section{$3.2{ }^{40} \mathrm{Ar} /{ }^{39} \mathrm{Ar}$ radiometric dating}

Hand samples of fresh rock were collected from all sites to deliver potential new ${ }^{40} \mathrm{Ar} /{ }^{39} \mathrm{Ar}$ radiometric age determinations. We selected 17 basalt samples for ${ }^{40} \mathrm{Ar} /{ }^{39} \mathrm{Ar}$ age determination based on their response to incremental heating age dating and the need for improved stratigraphic control. The experiments were carried out at the Argon Geochronology Laboratory at Oregon State University. A detailed description of the sample preparation and dating method is found in Supporting Information Section S1-1.

\subsection{Demagnetization experiments}

All palaeomagnetic laboratory work was carried out at the palaeomagnetic laboratories of Imperial College London (ICL) and University of Oxford. Upon cutting the samples, the natural remanent magnetization (NRM) was measured using an AGICO JR5A spinner magnetometer and a Molspin Minispin at ICL or a Molspin and 


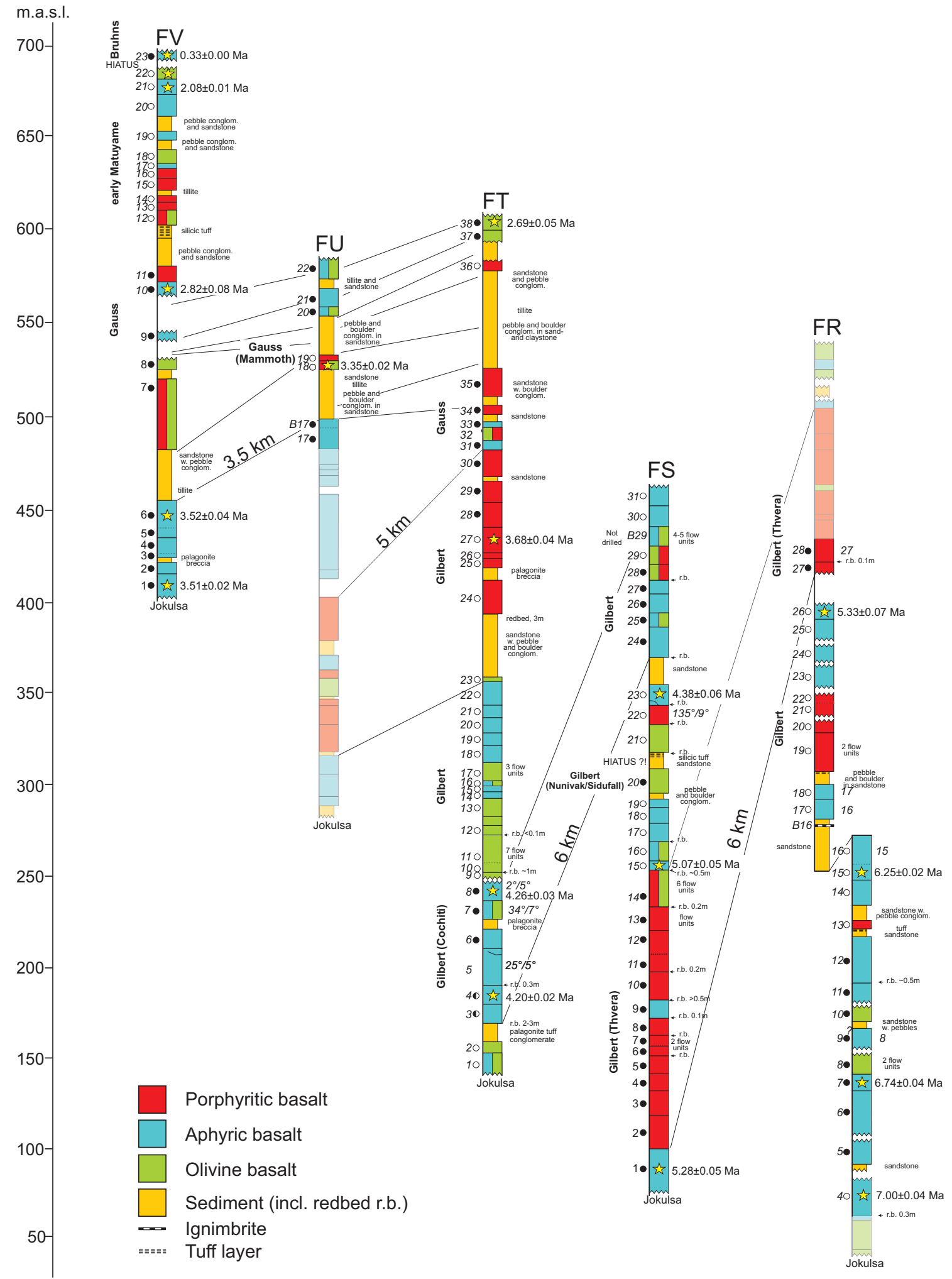

Figure 2. Updated magnetostratigraphy of sections FR to FV in Fljótsdalur based on the results presented here. Stratigraphic correlation of the sections is based on visual inspection in the field, site type geology as well as new palaeomagnetic directions and ${ }^{40} \mathrm{Ar} /{ }^{39} \mathrm{Ar}$ radiometric ages (this study). Labels to the left are site labels (this study). White(black) filled circles are magnetic reverse(normal) polarity based on virtual geomagnetic pole (VGP) polarity (this study). Labels to the right are Ar-Ar ages in Ma (this study) and on-site strike/dip measurements where possible (dip to the west). The updated stratigraphic correlation builds upon the original stratigraphy of Gudmundsson (1978). Please note that the base and top flows in section FR were not drilled due to time constraints and redundancy with section FS. Similarly, we only drilled the top flows in section FU due to redundancy of the base flows of section FU with flows in section FV. 


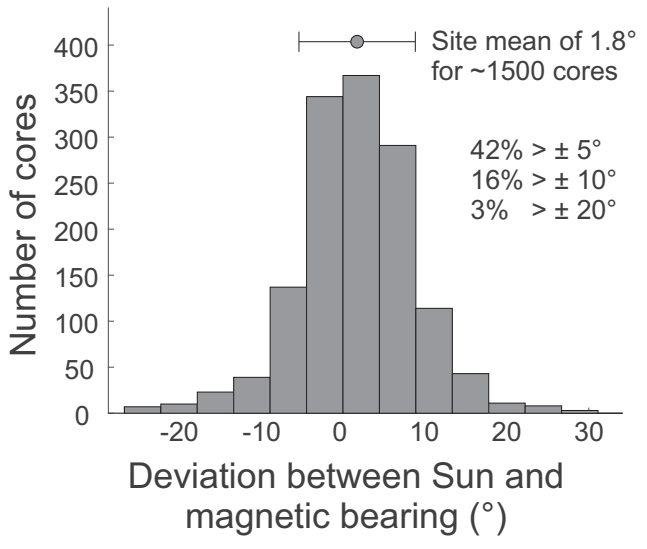

Figure 3. Histogram of difference between Sun and magnetic azimuth estimates for the $\sim 1500$ cores in this study.

three-axis $2 \mathrm{G}$ superconducting magnetometer at University of Oxford. Stepwise alternating-field (AF)- and thermal-demagnetization behaviours were measured on 1279 independent specimens from 125 sites for palaeodirectional analysis. Based on our results from Jökuldalur (Døssing et al. 2016), we subjected 1-2 specimens per site to thermal demagnetization using a magnetic measurements thermal demagnetiser (Oxford). The remainder of the specimens per site were subjected to AF magnetic cleaning using a Molspin Tumbling AF demagnetizer and a DTECH D-2000 high-performance $\mathrm{AF}$ demagnetizer at ICL, or a $2 \mathrm{G}$ magnetometer fitted with in-line AF-demagnetization coils at University of Oxford. Thermal- and AF-demagnetization experiments were carried out in 10-12 steps with maximum unblocking temperatures normally around $590{ }^{\circ} \mathrm{C}$ and within applied field magnitudes of 5-200 $\mathrm{mT}$ at ICL or 5-140 $\mathrm{mT}$ at Oxford. The 10-12 demagnetization steps were conducted to ensure proper removal of any viscous remanent magnetization and optimal determination of the characteristic remanent magnetization (ChRM) from principal component analysis (Kirschvink 1980).

\section{RESULTS}

\section{1 ${ }^{40} \mathrm{Ar} /{ }^{39} \mathrm{Ar}$ radiometric ages}

The 17 new high-resolution incremental heating ${ }^{40} \mathrm{Ar} /{ }^{39} \mathrm{Ar}$ age determinations are summarized in Table 1 and the age spectra are presented in Fig. 4. Assessments of each age-determination experiment are given in Supporting Information Section S1-2 along with inverse isochron diagrams (Supporting Information Fig. S1-1). The ArArCALC age calculation files will be made available for download from the EarthRef.org Digital Archive (ERDA).

In summary, the 17 new ${ }^{40} \mathrm{Ar} /{ }^{39} \mathrm{Ar}$ ages indicate that sections FR(FR4) to FV(FV23) span the interval of $7.00 \pm 0.04 \mathrm{Ma}$ to $334.4 \pm 4.2 \mathrm{Ka}$ (Table 1). A significant hiatus of 1.75 Myr is found between in the uppermost part of section FV between sites FV22 $(2.08 \pm 0.01 \mathrm{Ma})$ and FV23 $(334.4 \pm 4.2 \mathrm{Ka})$. Between 5 and 31 of the heating steps define the horizontal age plateaus that also include from 18 to 100 percent of the ${ }^{39} \mathrm{Ar}_{K}$ gas released. Six of the 17 groundmass separates failed to yield true plateau ages $(>50$ percent of the ${ }^{39} \mathrm{Ar}_{K}$ gas released) and for those samples we use the term mini-plateau age (weighted mean age) (Fig. 4). Fourteen out of 17 inverse isochron intercepts are within error of the 295.5 modern atmospheric ratio of ${ }^{40} \mathrm{Ar} /{ }^{36} \mathrm{Ar}$ (Supporting Information Section S1 and Fig. S1-1). For all but two experiments the K/Ca value decreases from the low-temperature steps through the age plateau to the high-temperature steps (Fig. 4); most likely a result from alteration phases that readily lose gas at low temperatures while argon retentive phases such as groundmass plagioclase and clinopyroxene tend to degas at high temperatures. Our approach resulted in high precision ages (with nominally $0.3-2.7$ per cent $2 \sigma$ uncertainties, including $J$-value errors).

The samples from sections FV, FU, FT and down to FS-15, with the exception of FV-6, generally yielded concordances in plateau, isochron and total fusion ages, indicating that the primary argon reservoirs were not significantly affected by alteration or recoil, and that the $\mathrm{K}-\mathrm{Ar}$ isotope system has effectively remained closed since the time of eruption (Fig. 4). The data show only modestly disturbed age spectra $\left({ }^{39} \mathrm{Ar}\right.$ recoil during irradiation), if disturbed at all. Sample FV-6 yielded a more disturbed age spectrum for which we defined a mini-plateau age of $3.52 \pm 0.04$ Ma $\left(26\right.$ per cent $\left.{ }^{39} \mathrm{Ar}_{K}\right)$. An alternative interpretation is a slightly older plateau age of 3.72 $\pm 0.06 \mathrm{Ma}$ (low-mid temperature steps, 56 percent ${ }^{39} \mathrm{Ar}_{K}$ ) that is concordant with an inverse isochron age of $3.74 \pm 0.10 \mathrm{Ma}$. However, this interpretation is at odds with the very concordant FV-1 age data of $3.51 \pm 0.02 \mathrm{Ma}\left(97\right.$ per cent ${ }^{39} \mathrm{Ar}_{K}$ ). Sample FS-1 and all samples from FR yielded disturbed age spectra, in particular FR-15, FR-7 and FR-4, hence rendering determination of the age of crystallization difficult. The groundmass material seems to be affected by both ${ }^{39} \mathrm{Ar}_{K}$ recoil during irradiation as well as argon loss likely caused by low-temperature alteration following burial in the lava pile. The latter is a common problem when attempting ${ }^{40} \mathrm{Ar} /{ }^{39} \mathrm{Ar}$ age determinations on material collected at low elevation from lava piles of Miocene age in Iceland. We define mini-plateau ages at lower-temperature steps for FR-15 (6.25 $\pm 0.02 \mathrm{Ma})$, FR-7 (6.74 $\pm 0.04 \mathrm{Ma})$ and FR-4 (7.00 $\pm 0.04 \mathrm{Ma})$, while alternative interpretations at higher-temperature steps with resultant younger ages (5.5-6.0 Ma for FR-7 and FR-4) can also be made. However, such young ages cannot be reconciled within the framework imposed by the magnetostratigraphy (Fig. 2) and absolute age constraints imposed by lava flows higher in the stratigraphy. Hence, we consider the reported plateau ages closer to the actual crystallization ages.

For comparison we have reassigned the ages for legacy ${ }^{40} \mathrm{Ar} /{ }^{39} \mathrm{Ar}$ age determinations reported by Ross \& Mussett (1976) and Mussett et al. (1980) on samples from these sections (V18-1, $2.09 \mathrm{Ma}$; V8-3a, 2.58 Ma; T17A-2a, 3.53 Ma; S19-1a, 4.68 Ma; R20A-2a, 4.62 Ma; R16-2a, 5.62 Ma; R5-2a, 6.01 Ma) by correcting for their reported decay constant and monitor standard age values so that the recalculated legacy age data is now comparable to the age determinations reported in Table 1 . The reassigned legacy ages reported for units FV18 and FV8 are broadly consistent with the ages that we report for this stratigraphic interval. Still, the reassigned age of FV8 is c. $200 \mathrm{kyr}$ younger than the plateau age for FV10 (with total fusion age of $2.56 \mathrm{Ma}$ ). We argue that the reported age for FV8 was somewhat influenced by argon loss. The reassigned age for FT17 is c. 200 kyr younger than FT27 (above) and c. 700800 kyr younger than FT8 (below). We regard the age of FT17 as unreliable and influenced by argon loss. The reassigned age for sample FS19 corroborates well with the ages that we report for FS15 and FS23. The reassigned ages for FR20, FR15 and FR5, however, are $0.7-1.0 \mathrm{Myr}$ younger than the age range implied for this stratigraphic interval by the new age determinations of FR26, FR15, FR7 and FR4. The reassigned ages are also consistently younger than the total fusion ages for FR26, FR15, FR7 and FR4. We attribute the young ages for FR20, FR15 and FR5 to the effects of argon loss and inadequate leaching pre-treatment. Deeply buried low-potassium basalts are notoriously challenging to obtain reliable $\mathrm{K} / \mathrm{Ar}$ and $\mathrm{Ar} / \mathrm{Ar}$ ages from, which is also evident from the complex 
Table 1. Incremental heating ${ }^{40} \mathrm{Ar} /{ }^{39} \mathrm{Ar}$ age determinations for basalts from Fljótsdalur. ID, experiment ID; gm, groundmass; $n$, the number of heating steps in the plateau; $\mathrm{N}$, total number of heating steps for the entire experiment. $\mathrm{K} / \mathrm{Ca}$ values are calculated as weighted means for the age spectra. MSWD values for the age plateaus and inverse isochrons are calculated using N-1 and N-2 degrees of freedom, respectively. All sample information from this study where monitored against FCT sanidine $(28.201 \pm 0.023 \mathrm{Ma}, 1 \sigma)$ as calibrated by Kuiper et al. (2008). Reported errors on the ${ }^{40} \mathrm{Ar} /{ }^{39} \mathrm{Ar}$ ages are on the 95 per cent confidence level $(2 \sigma)$ including $0.2-0.3$ per cent standard deviation in the $J$-value. All ages were calculated using the corrected Steiger \& Jäger (1977) decay constant of $5.530 \pm 0.097 \times 10^{-10} \mathrm{yr}^{-1}(2 \sigma)$ as reported by Min et al. (2000). For all other constants used in the age calculations we refer to Koppers et al. (2003). Incremental heating plateau ages and isochron ages were calculated as weighted means with $1 / \sigma^{2}$ as weighting factor (Taylor 1997) and as YORK2 least-squares fits with correlated errors (York 1968) using the ArArCALC v2.6.2 software from Koppers (2002) available from the http://earthref.org/ArArCALC/ website. Abbreviations: Mat: Material; Ic: Intercept.

\begin{tabular}{|c|c|c|c|c|c|c|c|c|c|c|c|c|c|}
\hline \multicolumn{3}{|c|}{ Sample inf } & \multicolumn{6}{|c|}{ Age spectrum } & \multicolumn{2}{|c|}{ Total fusion } & \multicolumn{3}{|c|}{ Inverse isochron } \\
\hline Site & ID & Mat & Age $\pm 2 \sigma(\mathrm{Ma})$ & ${ }^{39} \operatorname{Ar}(\%)$ & $\mathrm{K} / \mathrm{Ca}$ & MSWD & $n$ & $N$ & Age $\pm 2 \sigma(\mathrm{Ma})$ & $\mathrm{K} / \mathrm{Ca}$ & Age $\pm 2 \sigma(\mathrm{Ma})$ & ${ }^{40} \mathrm{Ar} /{ }^{36} \mathrm{Ar} \mathrm{Ic}$ & MSWD \\
\hline FV23 & 16D08339 & $\mathrm{gm}$ & $334.4 \pm 4.2 \mathrm{Ka}$ & 100.00 & 0.169 & 1.13 & 31 & 31 & $334.4 \pm 4.2 \mathrm{Ka}$ & 0.347 & $0.34 \pm 0.01$ & 294.85 & 1.14 \\
\hline FV21 & 16D08292 & gm & $2.08 \pm 0.01$ & 61.80 & 0.102 & 1.41 & 15 & 31 & $2.08 \pm 0.01$ & 0.122 & $2.05 \pm 0.07$ & 301.72 & 1.44 \\
\hline FV10 & 16D08219 & gm & $2.82 \pm 0.08$ & 50.45 & 0.016 & 1.57 & 15 & 31 & $2.56 \pm 0.06$ & 0.023 & $2.65 \pm 0.16$ & 298.86 & 1.17 \\
\hline FV6 & 16D08172 & gm & $3.52 \pm 0.04$ & 25.72 & 0.037 & 1.01 & 8 & 31 & $3.54 \pm 0.04$ & 0.062 & $3.80 \pm 0.32$ & 279.36 & 0.72 \\
\hline FV1 & 16D08125 & gm & $3.51 \pm 0.02$ & 97.00 & 0.030 & 0.81 & 27 & 31 & $3.65 \pm 0.03$ & 0.033 & $3.51 \pm 0.04$ & 295.27 & 0.84 \\
\hline FU18 & 16D08386 & gm & $3.35 \pm 0.02$ & 97.47 & 0.034 & 0.76 & 28 & 31 & $3.49 \pm 0.03$ & 0.038 & $3.33 \pm 0.03$ & 297.40 & 0.67 \\
\hline FT38 & $16 \mathrm{D} 08078$ & gm & $2.69 \pm 0.05$ & 57.10 & 0.024 & 1.02 & 13 & 31 & $2.85 \pm 0.06$ & 0.022 & $2.60 \pm 0.13$ & 300.05 & 0.90 \\
\hline FT27 & 16D08005 & gm & $3.68 \pm 0.04$ & 92.56 & 0.022 & 0.60 & 24 & 31 & $3.95 \pm 0.05$ & 0.019 & $3.68 \pm 0.05$ & 295.74 & 0.63 \\
\hline FT8 & 16D07958 & gm & $4.26 \pm 0.03$ & 85.19 & 0.043 & 0.93 & 23 & 31 & $4.20 \pm 0.04$ & 0.034 & $4.28 \pm 0.05$ & 294.33 & 0.94 \\
\hline FT4 & 16D07911 & gm & $4.20 \pm 0.02$ & 78.44 & 0.050 & 1.19 & 18 & 31 & $4.15 \pm 0.02$ & 0.054 & $4.22 \pm 0.05$ & 294.11 & 1.24 \\
\hline FS23 & $16 \mathrm{D} 06588$ & $\mathrm{gm}$ & $4.38 \pm 0.06$ & 58.92 & 0.046 & 2.09 & 19 & 32 & $4.44 \pm 0.05$ & 0.048 & $4.40 \pm 0.30$ & 295.12 & 2.21 \\
\hline FS15 & 16D06513 & gm & $5.07 \pm 0.05$ & 50.97 & 0.029 & 1.16 & 13 & 32 & $5.13 \pm 0.05$ & 0.023 & $5.10 \pm 0.44$ & 294.48 & 1.26 \\
\hline FS1 & $16 \mathrm{D} 07070$ & $\mathrm{gm}$ & $5.28 \pm 0.05$ & 42.50 & 0.075 & 2.52 & 12 & 31 & $5.39 \pm 0.03$ & 0.069 & $5.41 \pm 0.14$ & 288.72 & 1.98 \\
\hline FR26 & 16D07117 & gm & $5.33 \pm 0.07$ & 24.56 & 0.025 & 1.51 & 12 & 31 & $5.72 \pm 0.02$ & 0.097 & $5.53 \pm 0.14$ & 292.42 & 0.78 \\
\hline FR15 & 16D06466 & gm & $6.25 \pm 0.02$ & 30.58 & 0.168 & 2.56 & 7 & 31 & $6.05 \pm 0.01$ & 0.141 & $6.25 \pm 0.14$ & 297.58 & 3.08 \\
\hline FR7 & $16 \mathrm{D} 06415$ & gm & $6.74 \pm 0.04$ & 30.51 & 0.165 & 6.26 & 6 & 34 & $6.39 \pm 0.02$ & 0.093 & $6.78 \pm 0.17$ & 286.67 & 7.36 \\
\hline FR4 & 15D35592 & gm & $7.00 \pm 0.04$ & 17.89 & 0.246 & 1.91 & 5 & 32 & $6.28 \pm 0.05$ & 0.198 & $6.98 \pm 0.15$ & 297.09 & 2.43 \\
\hline
\end{tabular}

disturbed ${ }^{39} \mathrm{Ar}$ release patterns reported here for FR15, FR7 and FR4. On this note, it is with some hesitance that we dismiss the legacy ages. In summary, our interpretations of the 17 new ${ }^{40} \mathrm{Ar} /{ }^{39} \mathrm{Ar}$ age determinations show that the composite stratigraphic section from base of FR to top FV span the interval of $7.00 \pm 0.04 \mathrm{Ma}$ to $0.33 \pm 0.00 \mathrm{Ma}$, thereby extending the previously established absolute age range (Dagley et al. 1967; Watkins \& Walker 1977; Mussett et al. 1980) by one Myr.

The intersection stratigraphic correlations presented in Fig. 2 are based on the combined observations of lithostratigraphy (distinct traceable lava groups and sedimentary deposits), magnetostratigraphy and absolute age determinations, and builds on the work by Watkins \& Walker (1977) and Gudmundsson (1978). Hiatuses or periods characterized by no or little volcanic activity are identified throughout the composite stratigraphy with: (i) major hiatuses (>500 kyr duration) between FV22-23, FV11-12, FV6-9/FUB1720/FT35-FT37, FS19-21 and between FR16-17, and (ii) minor hiatuses ( $\leq$ c. 350 kyr) between FT23-24, FT2-3/FS23-24, FR12-13 and between FR4-5. The major hiatus identified in FV, FU and FT consists of two briefer hiatuses with sporadic volcanic products in-between. The intermittent volcanic products are of variable age and magnetic polarity, reflecting a decrease in lateral continuity in volcanic units during the late Pliocene and Pleistocene because of increased topographic relief, (glacial) erosion and interaction between volcanism and ice cover. In the discussion we present a magneto-chronostratigraphic age model for the composite stratigraphic section in Fljótsdalur.

\subsection{Palaeodirections}

We analysed the demagnetization data using Puffinplot (Lurcock \& Wilson 2012) and determined the direction of the characteristic remanent magnetization (ChRM) using principal component analysis (Kirschvink 1980). Five or more points were used and only directions trending to the origin with a maximum angle of deviation (MAD) $<5^{\circ}$ were accepted. Two sites were discarded from the analysis due poor demagnetization results. A total of 1165 independent directions were accepted from 123 sites, with mean, minimum (min) and maximum (max) number $(\mathrm{N})$ of independent ChRMs per site $N_{\text {mean }}=9.5, N_{\text {min }}=5$ and $N_{\max }=14$, respectively (Fig. 5a). Typical stepwise AF- and thermal-demagnetization plots are shown in Fig. 5(b)-(g). As shown, the magnetic remanence generally resides in a stable single component of magnetization acquired during original cooling. A secondary viscous component of smaller magnitude was generally removed by AF-demagnetization peak fields of 5-10 $\mathrm{mT}$ or temperatures of $\sim 250{ }^{\circ} \mathrm{C}$. These results are similar to the observations obtained by Døssing et al. (2016) from Jökuldalur and on extrusive basaltic rocks from other palaeomagnetic studies in Iceland (Kristjánsson 2008; Linder \& Leonhardt 2009).

We corrected the ChRM directions for a post-emplacement tectonic westerly (azimuth $=280^{\circ}$ ) dip of $2.5^{\circ}-8.0^{\circ}$. For this we used a handful of in situ dip measurements and the eastern Iceland dipversus-age model of Watkins \& Walker (1977) using our updated magnetostratigraphic age model for sections FR to FV (see Section $5)$.

We also computed the site palaeolatitude by correcting the present-day site latitudes for a (very) small post-emplacement plate kinematic movement. We used the NNR-MORVEL56 plate motion model of Argus et al. (2011), which is a set of angular velocities relative to the unique reference frame in which there is no net rotation of the lithosphere. According to NNRMORVEL56, eastern Iceland (Eurasia Plate) is currently moving in a north-northeasterly direction with a speed and azimuth of $18.28 \mathrm{~mm} \mathrm{yr}^{-1}$ and 26.98, respectively. This movement transfers into a northward velocity of $16.29 \mathrm{~mm} \mathrm{yr}^{-1}$ and an eastward velocity $8.29 \mathrm{~mm} \mathrm{yr}^{-1}$ as obtained using the online plate motion calculator of UNAVCO (https://www.unavco.org/software/geodetic-u tilities/plate-motion-calculator/plate-motion-calculator.html). The plate kinematic correction implies that the true site latitude and 

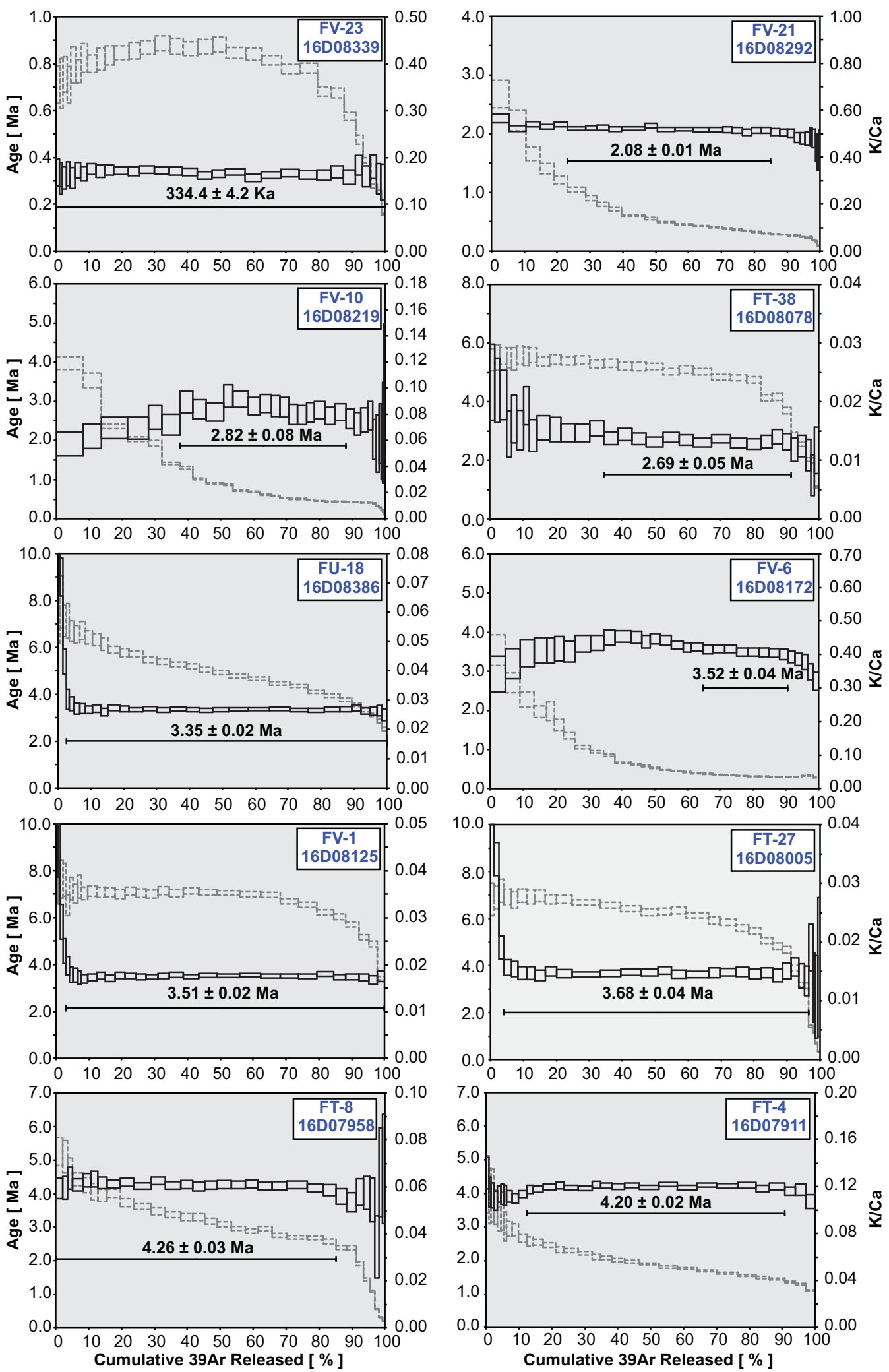

Figure 4. High-resolution incremental heating ${ }^{40} \mathrm{Ar} /{ }^{39} \mathrm{Ar}$ age spectra on groundmass separates subaerial basalt samples from profiles FV, FU, FT, FS and FR in Fljótsdalur, eastern Iceland. The age spectra are presented in stratigraphic order from young to old in the lava pile. The ${ }^{40} \mathrm{Ar} /{ }^{39} \mathrm{Ar}$ ages are weighted age estimates with errors reported at the 95 per cent confidence level, including $0.2-0.3$ per cent standard deviations in the $J$-value. All samples were monitored against FCT sanidine $(28.201 \pm 0.023 \mathrm{Ma}, 1 \sigma)$ as calibrated by Kuiper et al. (2008). Solid black lines are ${ }^{40} \mathrm{Ar} /{ }^{39} \mathrm{Ar}$ ages and stippled gray lines are $\mathrm{K} / \mathrm{Ca}$ values. Data are listed in Table 1 and ArArCALC age calculation files will be made available for download from the EarthRef.org Digital Archive (ERDA) and GEOCHRON. 
(a)

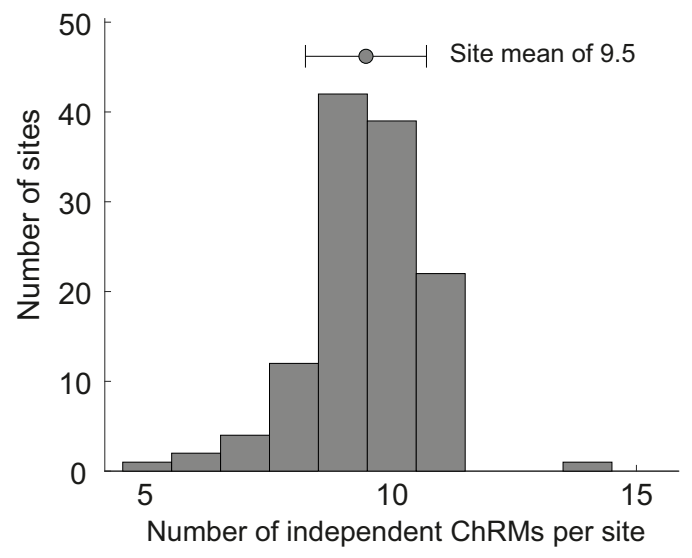

(d)
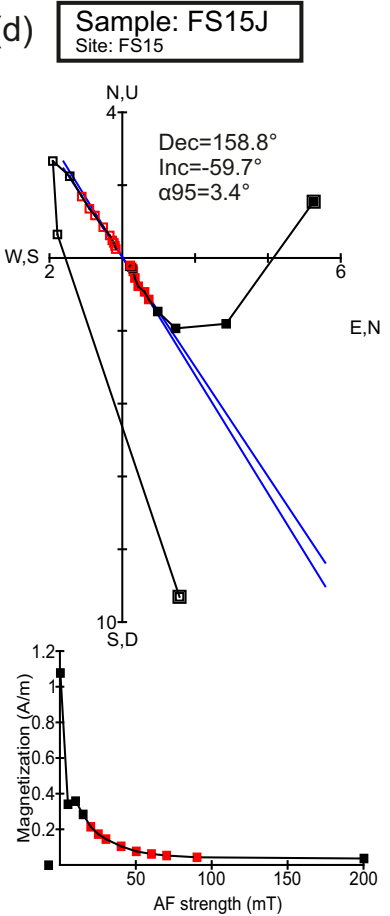

(e)

Sample:
Site: FR19 (b)
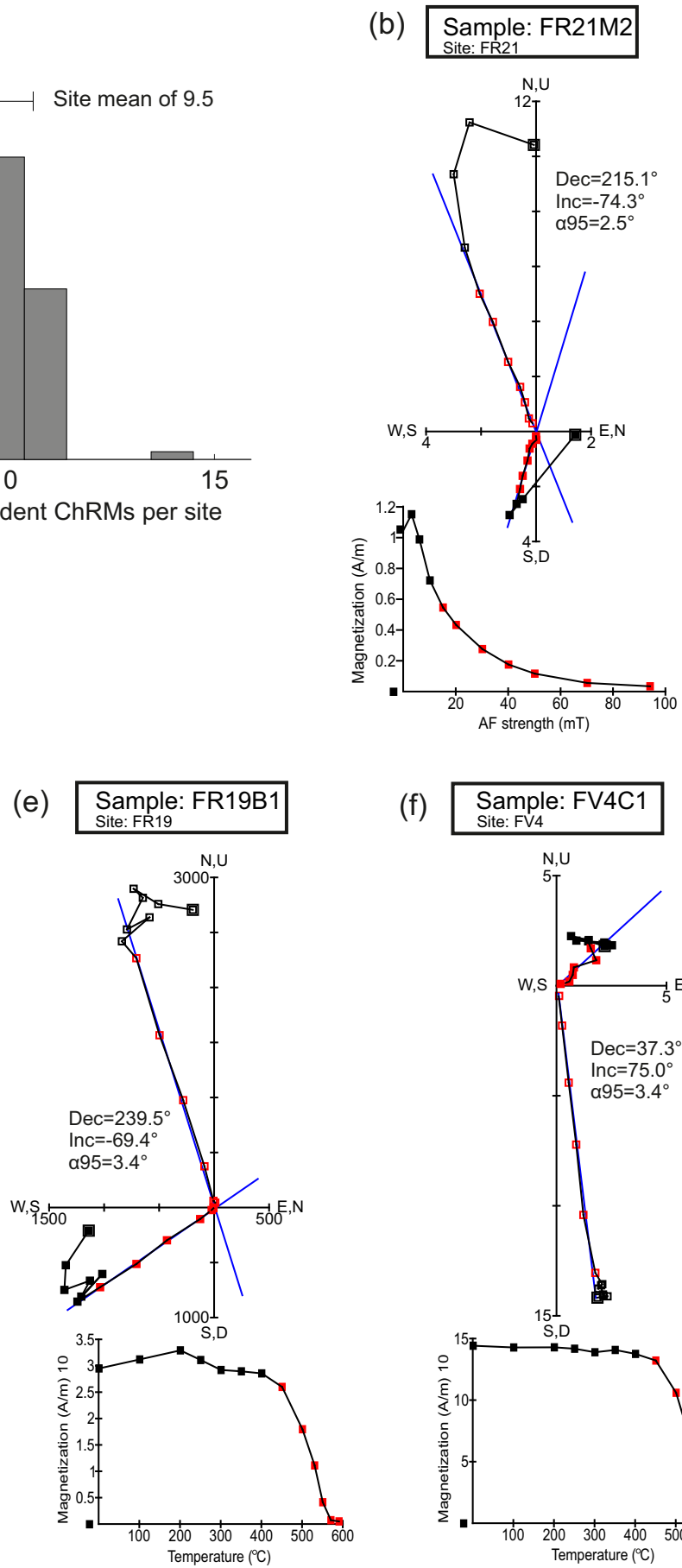

(f)
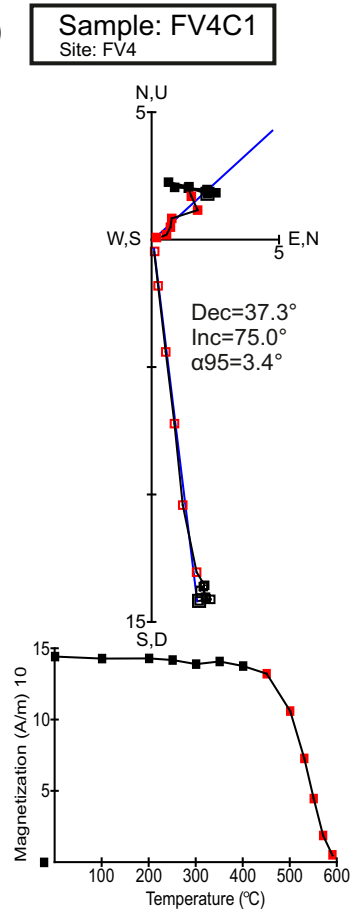

(c) Sample: FS14G Site: FS14

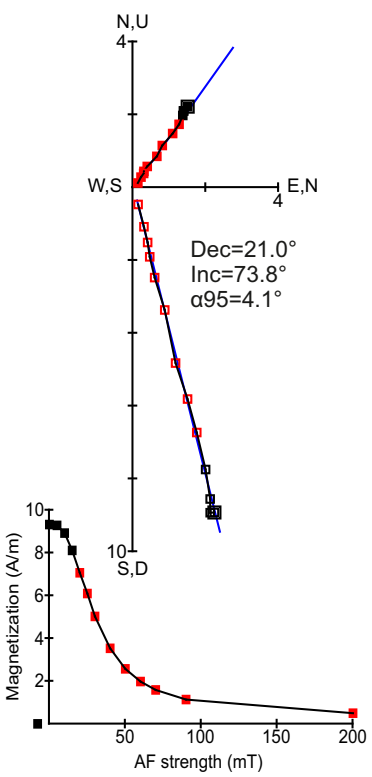

(g)
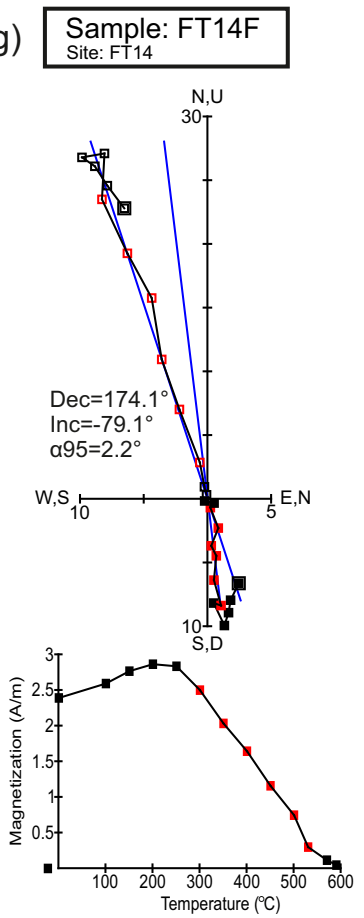

Figure 5. (a) Histogram of independent successful ChRM directions per site for the accepted 123 sites. (b)-(g) Examples of typical evolution of direction and intensity of the natural remanent magnetization during AF demagnetization (b-d) and thermal demagnetization (e-g).

longitude at the time of the rock formation are located to the southsouthwest of the present-day site location. For the oldest site, FR4, the plate kinematic latitude correction is -1.0 , while the longitude correction is -1.2 . For this study, we assume that the plate motions defined by the NNR-MORVEL56 model are valid for the period represented by sites in this study.

The 123 accepted mean site directions were calculated using Fisher (1953) statistics by averaging AF and thermal results. The results are shown in Table 2 together with the corresponding VGPs. A summary of the site mean statistics, including $n, k$,
Declination, Inclination, VGP latitude and polarity corrected for post-emplacement tectonic movements, is shown for each section in Fig. 6. In Fig. 7, we plot the site mean directions and VGPs for data corrected for post-emplacement tectonic movements (Supporting Information Fig. S2-3 shows the corresponding plot for data not corrected for post-emplacement tectonic movements).

As shown in Figs 6 and 7 we obtain well-grouped ChRM directions for all sites with $n_{\text {mean }}=9.5\left(n_{\min }=5, n_{\text {max }}=14\right), k_{\text {mean }}$ $=353\left(k_{\min }=47, k_{\max }=1383\right)$ and $\alpha 95_{\text {mean }}=3.1^{\circ}\left(\alpha 95_{\min }=\right.$ $\left.1.4^{\circ}, \alpha 95_{\max }=9.6^{\circ}\right)$, where $k$ is the precision parameter and $\alpha 95$ 
Table 2. Fljótsdalur palaeodirectional site statistics. Site: Site name. Elev: GPS-altitudes (m). Azi/Dip: Azimuth $\left({ }^{\circ}\right)$ and $\operatorname{dip}\left({ }^{\circ}\right)$ of bedding. SLon $\left({ }^{\circ} \mathrm{N}\right) / \mathrm{SLat}\left({ }^{\circ} \mathrm{E}\right)$ : Site Longitude/Latitude $\left({ }^{\circ}\right)$. SLon $\left({ }^{\circ} \mathrm{N}\right) / \mathrm{SLat}\left({ }^{\circ} \mathrm{E}\right)$ : Site Longitude/Latitude $\left({ }^{\circ}\right)$ corrected for plate motions using the NNR-MORVEL56 model (Argus et al. 2011). N: Total number of independent ChRMs per site. D/I: Site mean declination $\left({ }^{\circ}\right) /$ inclination $\left({ }^{\circ}\right)$. $\mathrm{D}^{\prime} / \mathrm{I}^{\prime}$ : Site mean declination $\left(^{\circ}\right) /$ inclination $\left({ }^{\circ}\right)$ corrected for bedding tilt. $\alpha 95\left(^{\circ}\right)$ Fisher (1953) circle of $95 \%$ confidence. $k$ : Estimate of the Fisher (1953) precision parameter. $R$ : Length of the vector sum, or resultant vector R (Fisher 1953). VLon/VLat: Virtual geomagnetic pole position $\left({ }^{\circ}\right) . d p / d m$ : $95 \%$ confidence angles $\left(^{\circ}\right.$ ) in parallel and meridian. Pol: Polarity. MAge: Model age(Ma)/Chron (B, Brunhes; M, Matuyama; Ga, Gauss, Gi, Gilbert, Mi, Miocene) - see Section 5. Sites removed for further analysis due to statistical overlap with sites immediately above/below or comparable sites in other sections:FR16, FR22, FS2,FS29,FT37,FUB17,FU22,FV4,FV6,FV9.

\begin{tabular}{|c|c|c|c|c|c|c|c|c|c|c|c|c|c|c|c|c|c|c|c|}
\hline Site & Elev & Azi/Dip & SLon & SLat & SLon' & SLat' & $\mathrm{N}$ & $\mathrm{D}$ & I & $\mathrm{D}^{\prime}$ & $I^{\prime}$ & $\alpha 95$ & $\mathrm{k}$ & $\mathrm{R}$ & VLon & VLat & $\mathrm{d} p / \mathrm{d} m$ & Pol. & MAge \\
\hline$\overline{\text { FV23 }}$ & 680 & $280 / 0.0$ & -15.39350 & 64.88557 & -15.45956 & 64.83145 & 10 & 254 & 88 & 254 & 88 & 3.0 & 267 & 10 & 337 & 64 & $5.9 / 5.9$ & $\mathrm{~N}$ & $0.37 / \mathrm{B}$ \\
\hline FV22 & 653 & $280 / 2.5$ & -15.38992 & 64.88903 & -15.75638 & 64.58416 & 11 & 218 & -70 & 212 & -71 & 2.9 & 252 & 11 & 269 & -72 & $4.4 / 5$ & $\mathrm{R}$ & $2.08 / \mathrm{M}$ \\
\hline FV21 & 644 & $280 / 2.6$ & -15.38600 & 64.88933 & -15.75438 & 64.58249 & 11 & 233 & -74 & 226 & -76 & 2.5 & 333 & 11 & 239 & -70 & $4.2 / 4.6$ & $\mathrm{R}$ & $2.10 / \mathrm{M}$ \\
\hline FV20 & 628 & $280 / 2.7$ & -15.38025 & 64.88880 & -15.75193 & 64.57954 & 10 & 208 & -69 & 202 & -70 & 2.7 & 315 & 10 & 290 & -74 & $4 / 4.7$ & $\mathrm{R}$ & $2.12 / \mathrm{M}$ \\
\hline FV19 & 619 & $280 / 2.7$ & -15.37763 & 64.88877 & -15.75193 & 64.57787 & 8 & 218 & -78 & 206 & -79 & 4.8 & 132 & 8 & 217 & -79 & $8.8 / 9.2$ & $\mathrm{R}$ & $2.13 / \mathrm{M}$ \\
\hline FV18 & 603 & $280 / 2.8$ & -15.37145 & 64.88752 & -15.74848 & 64.57392 & 9 & 194 & -74 & 184 & -74 & 1.9 & 772 & 9 & 320 & -85 & $3 / 3.3$ & $\mathrm{R}$ & $2.15 / \mathrm{M}$ \\
\hline FV17 & 599 & $280 / 2.8$ & -15.37118 & 64.88745 & -15.74937 & 64.57218 & 9 & 287 & -85 & 296 & -88 & 3.1 & 274 & 9 & 172 & -63 & $6.2 / 6.2$ & $\mathrm{R}$ & $2.15 / \mathrm{M}$ \\
\hline FV16 & 597 & $280 / 2.9$ & -15.37037 & 64.88745 & -15.74882 & 64.57181 & 10 & 202 & -81 & 184 & -81 & 2.6 & 345 & 10 & 172 & -82 & $4.9 / 5$ & $\mathrm{R}$ & $2.16 / \mathrm{M}$ \\
\hline FV15 & 590 & $280 / 2.9$ & -15.36902 & 64.88747 & -15.74937 & 64.57052 & 10 & 170 & -87 & 138 & -85 & 2.5 & 369 & 10 & 143 & -71 & $4.9 / 5$ & $\mathrm{R}$ & $2.16 / \mathrm{M}$ \\
\hline FV14 & 582 & $280 / 2.9$ & -15.36848 & 64.88752 & -15.75015 & 64.57004 & 10 & 135 & -74 & 130 & -72 & 3.2 & 224 & 10 & 80 & -65 & $5 / 5.7$ & $\mathrm{R}$ & $2.17 / \mathrm{M}$ \\
\hline FV13 & 579 & $280 / 3.0$ & -15.36658 & 64.88683 & -15.74981 & 64.56848 & 9 & 235 & -71 & 229 & -73 & 1.4 & 1384 & 9 & 245 & -67 & $2.2 / 2.5$ & $\mathrm{R}$ & $2.18 / \mathrm{M}$ \\
\hline FV12 & 574 & $280 / 3.0$ & -15.36557 & 64.88638 & -15.74992 & 64.56656 & 11 & 234 & -68 & 228 & -70 & 2.9 & 249 & 11 & 256 & -64 & $4.3 / 5$ & $\mathrm{R}$ & $2.18 / \mathrm{M}$ \\
\hline FV11 & 559 & $280 / 3.1$ & -15.36282 & 64.88582 & -15.85091 & 64.48004 & 10 & 193 & 83 & 216 & 82 & 2.6 & 349 & 10 & 330 & 51 & $4.9 / 5$ & $\mathrm{~N}$ & $2.78 / \mathrm{Ga}$ \\
\hline FV10 & 550 & $280 / 3.1$ & -15.35525 & 64.88577 & -15.84491 & 64.47838 & 11 & 55 & 76 & 45 & 78 & 2.3 & 411 & 11 & 45 & 72 & $4 / 4.3$ & $\mathrm{~N}$ & $2.79 / \mathrm{Ga}$ \\
\hline FV9 & 534 & $280 / 3.3$ & -15.34385 & 64.88967 & -15.83613 & 64.48053 & 9 & 24 & 67 & 16 & 68 & 1.6 & 1016 & 9 & 125 & 74 & $2.3 / 2.7$ & $\mathrm{~N}$ & $2.80 / \mathrm{Ga}$ \\
\hline FV8 & 526 & $280 / 3.3$ & -15.33105 & 64.88898 & -15.87949 & 64.43263 & 9 & 41 & 75 & 29 & 77 & 2.4 & 482 & 9 & 61 & 78 & $4 / 4.4$ & $\mathrm{~N}$ & $3.12 / \mathrm{Ga}$ \\
\hline FV7 & 520 & $280 / 3.3$ & -15.32545 & 64.89097 & -15.87838 & 64.43057 & 8 & 13 & 68 & 4 & 68 & 1.9 & 821 & 8 & 152 & 76 & $2.7 / 3.2$ & $\mathrm{~N}$ & $3.15 / \mathrm{Ga}$ \\
\hline FV6 & 447 & $280 / 3.8$ & -15.32338 & 64.89190 & -15.94924 & 64.37094 & 8 & 16 & 78 & 358 & 78 & 3.9 & 203 & 8 & 329 & 87 & $6.9 / 7.3$ & $\mathrm{~N}$ & $3.56 / \mathrm{Ga}$ \\
\hline FV5 & 437 & $280 / 3.9$ & -15.32447 & 64.89220 & -15.95246 & 64.36909 & 9 & 18 & 77 & 1 & 77 & 2.8 & 330 & 9 & 6 & 89 & $4.9 / 5.3$ & $\mathrm{~N}$ & $3.58 / \mathrm{Gi}$ \\
\hline FV4 & 433 & $280 / 3.9$ & -15.32173 & 64.89175 & -15.95135 & 64.36835 & 9 & 37 & 75 & 23 & 76 & 3.4 & 234 & 9 & 65 & 80 & $5.8 / 6.2$ & $\mathrm{~N}$ & $3.58 / \mathrm{Gi}$ \\
\hline FV3 & 429 & $280 / 3.9$ & -15.32192 & 64.89182 & -15.95224 & 64.36761 & 9 & 32 & 75 & 17 & 76 & 2.6 & 408 & 9 & 77 & 82 & $4.3 / 4.7$ & $\mathrm{~N}$ & $3.59 / \mathrm{Gi}$ \\
\hline FV2 & 422 & $280 / 4.0$ & -15.31980 & 64.89117 & -15.95179 & 64.36532 & 10 & 52 & 87 & 337 & 87 & 2.1 & 510 & 10 & 337 & 70 & $4.2 / 4.3$ & $\mathrm{~N}$ & $3.59 / \mathrm{Gi}$ \\
\hline FV1 & 415 & $280 / 4.0$ & -15.31887 & 64.89122 & -15.95235 & 64.36403 & 8 & 340 & 80 & 324 & 77 & 2.9 & 368 & 8 & 275 & 75 & $5 / 5.4$ & $\mathrm{~N}$ & $3.60 / \mathrm{Gi}$ \\
\hline FU22 & 585 & $280 / 3.5$ & -15.28667 & 64.92367 & -15.77135 & 64.52100 & 9 & 38 & 66 & 31 & 67 & 2.6 & 408 & 9 & 102 & 68 & $3.5 / 4.2$ & $\mathrm{~N}$ & $2.76 / \mathrm{Ga}$ \\
\hline FU21 & 562 & $280 / 3.6$ & -15.28242 & 64.92143 & -15.77413 & 64.51153 & 10 & 22 & 65 & 14 & 65 & 2.7 & 324 & 10 & 133 & 71 & $3.5 / 4.4$ & $\mathrm{~N}$ & $2.80 / \mathrm{Ga}$ \\
\hline FU20 & 542 & $280 / 3.7$ & -15.28193 & 64.92042 & -15.77635 & 64.50868 & 10 & 349 & 79 & 333 & 78 & 3.0 & 264 & 10 & 274 & 79 & $5.2 / 5.6$ & $\mathrm{~N}$ & $2.81 / \mathrm{Ga}$ \\
\hline FU19 & 535 & $280 / 3.8$ & -15.28102 & 64.91925 & -15.86872 & 64.42999 & 11 & 128 & -53 & 126 & -50 & 2.5 & 328 & 11 & 56 & -43 & $2.2 / 3.4$ & $\mathrm{R}$ & $3.34 / \mathrm{Ga}$ \\
\hline FU18 & 530 & $280 / 3.8$ & -15.27855 & 64.91848 & -15.86783 & 64.42807 & 9 & 287 & -62 & 289 & -66 & 3.6 & 201 & 9 & 215 & -36 & $4.9 / 6$ & $\mathrm{R}$ & $3.35 / \mathrm{Ga}$ \\
\hline FUB17 & 502 & $280 / 3.9$ & -15.27740 & 64.91600 & -15.90324 & 64.39494 & 11 & 348 & 80 & 332 & 78 & 2.9 & 249 & 11 & 277 & 78 & $5.1 / 5.4$ & $\mathrm{~N}$ & $3.56 / \mathrm{Ga}$ \\
\hline FU17 & 487 & $280 / 4.0$ & -15.27733 & 64.91462 & -15.90657 & 64.39117 & 10 & 360 & 78 & 343 & 77 & 2.5 & 384 & 10 & 263 & 83 & $4.3 / 4.6$ & $\mathrm{~N}$ & $3.58 / \mathrm{Gi}$ \\
\hline FT38 & 598 & $280 / 3.0$ & -15.26613 & 64.94217 & -15.75035 & 64.53900 & 5 & 37 & 68 & 30 & 69 & 3.5 & 483 & 5 & 98 & 70 & $5 / 5.9$ & $\mathrm{~N}$ & $2.76 / \mathrm{Ga}$ \\
\hline FT37 & 585 & $280 / 3.1$ & -15.25433 & 64.94293 & -15.74613 & 64.53353 & 8 & 27 & 64 & 21 & 65 & 2.8 & 406 & 8 & 122 & 69 & $3.6 / 4.4$ & $\mathrm{~N}$ & $2.80 / \mathrm{Ga}$ \\
\hline FT36 & 579 & $280 / 3.1$ & -15.24445 & 64.94300 & -15.78627 & 64.49181 & 10 & 156 & -78 & 145 & -77 & 1.9 & 667 & 10 & 90 & -75 & $3.2 / 3.5$ & $\mathrm{R}$ & $3.09 / \mathrm{Ga}$ \\
\hline FT35 & 512 & $280 / 3.6$ & -15.21183 & 64.94888 & -15.83469 & 64.43090 & 9 & 12 & 84 & 342 & 83 & 2.6 & 395 & 9 & 325 & 77 & $5 / 5.1$ & $\mathrm{~N}$ & $3.54 / \mathrm{Ga}$ \\
\hline FT34 & 496 & $280 / 3.7$ & -15.21082 & 64.94815 & -15.83724 & 64.42694 & 10 & 10 & 73 & 358 & 73 & 3.2 & 225 & 10 & 173 & 84 & $5.1 / 5.7$ & $\mathrm{~N}$ & $3.56 / \mathrm{Ga}$ \\
\hline FT33 & 490 & $280 / 3.7$ & -15.21037 & 64.94782 & -15.83757 & 64.42583 & 9 & 84 & 80 & 75 & 83 & 2.0 & 654 & 9 & 15 & 65 & $3.9 / 3.9$ & $\mathrm{~N}$ & $3.57 / \mathrm{Gi}$ \\
\hline FT32 & 484 & $280 / 3.8$ & -15.20927 & 64.94767 & -15.83791 & 64.42472 & 11 & 324 & 60 & 320 & 57 & 2.2 & 446 & 11 & 225 & 5 & $2.3 / 3.2$ & $\mathrm{~N}$ & $3.58 / \mathrm{Gi}$ \\
\hline FT31 & 479 & $280 / 3.8$ & -15.20887 & 64.94755 & -15.83902 & 64.42380 & 9 & 345 & 84 & 322 & 81 & 2.6 & 390 & 9 & 303 & 74 & $4.9 / 5$ & $\mathrm{~N}$ & $3.58 / \mathrm{Gi}$ \\
\hline FT30 & 460 & $280 / 3.9$ & -15.20768 & 64.94743 & -15.84224 & 64.41929 & 11 & 304 & 74 & 300 & 71 & 2.1 & 481 & 11 & 265 & 59 & $3.1 / 3.6$ & $\mathrm{~N}$ & $3.61 / \mathrm{Gi}$ \\
\hline FT29 & 446 & $280 / 4.0$ & -15.20573 & 64.94803 & -15.84335 & 64.41770 & 10 & 68 & 69 & 61 & 72 & 4.0 & 147 & 10 & 60 & 60 & $6.2 / 7$ & $\mathrm{~N}$ & 3.63/Gi \\
\hline FT28 & 439 & $280 / 4.1$ & -15.20563 & 64.94795 & -15.84490 & 64.41641 & 10 & 234 & 75 & 243 & 72 & 2.8 & 308 & 10 & 305 & 41 & $4.3 / 4.9$ & $\mathrm{~N}$ & $3.63 / \mathrm{Gi}$ \\
\hline FT27 & 420 & $280 / 4.2$ & -15.20387 & 64.94783 & -15.84712 & 64.41289 & 11 & 235 & -71 & 225 & -74 & 3.3 & 198 & 11 & 244 & -69 & $5.3 / 5.9$ & $\mathrm{R}$ & $3.66 / \mathrm{Gi}$ \\
\hline FT26 & 416 & $280 / 4.2$ & -15.20415 & 64.94813 & -15.84801 & 64.41215 & 8 & 239 & -68 & 232 & -71 & 3.8 & 209 & 8 & 250 & -63 & $5.8 / 6.7$ & $\mathrm{R}$ & $3.66 / \mathrm{Gi}$ \\
\hline FT25 & 398 & $280 / 4.4$ & -15.20352 & 64.94825 & -15.85201 & 64.40883 & 9 & 198 & -82 & 170 & -81 & 2.7 & 371 & 9 & 144 & -81 & $5 / 5.2$ & $\mathrm{R}$ & $3.69 / \mathrm{Gi}$ \\
\hline FT24 & 380 & $280 / 4.5$ & -15.20222 & 64.94828 & -15.85401 & 64.40550 & 9 & 170 & -46 & 166 & -44 & 2.6 & 399 & 9 & 5 & -51 & $2 / 3.2$ & $\mathrm{R}$ & $3.71 / \mathrm{Gi}$ \\
\hline FT23 & 343 & $280 / 4.7$ & -15.19855 & 64.94915 & -15.91371 & 64.35433 & 9 & 169 & -62 & 161 & -60 & 1.9 & 750 & 9 & 18 & -65 & & $\mathrm{R}$ & $4.07 / \mathrm{Gi}$ \\
\hline FT22 & 337 & $280 / 4.8$ & -15.19777 & 64.94907 & -15.91405 & 64.35322 & 9 & 122 & -76 & 116 & -72 & 2.9 & 317 & 9 & 90 & -59 & $4.5 / 5.1$ & $\mathrm{R}$ & $4.07 / \mathrm{Gi}$ \\
\hline FT21 & 325 & $280 / 4.8$ & -15.19763 & 64.94895 & -15.91671 & 64.35100 & 10 & 203 & -80 & 174 & -80 & 2.8 & 300 & 10 & 149 & -83 & $5.1 / 5.4$ & $\mathrm{R}$ & $4.09 / \mathrm{Gi}$ \\
\hline FT20 & 322 & $280 / 4.9$ & -15.19740 & 64.94880 & -15.91638 & 64.35045 & 9 & 229 & -70 & 217 & -73 & 3.4 & 233 & 9 & 256 & -72 & $5.4 / 6$ & $\mathrm{R}$ & $4.09 / \mathrm{Gi}$ \\
\hline FT19 & 309 & $280 / 5.0$ & -15.19758 & 64.94870 & -15.91871 & 64.34934 & 9 & 245 & -67 & 237 & -71 & 3.9 & 176 & 9 & 246 & -61 & $5.9 / 6.8$ & $\mathrm{R}$ & $4.10 / \mathrm{Gi}$ \\
\hline FT18 & 314 & $280 / 4.9$ & -15.19678 & 64.94875 & -15.91860 & 64.34860 & 10 & 182 & -82 & 153 & -80 & 3.2 & 233 & 10 & 116 & -78 & $5.8 / 6.1$ & $\mathrm{R}$ & $4.11 / \mathrm{Gi}$ \\
\hline FT17 & 298 & $280 / 5.0$ & -15.19682 & 64.94848 & -15.92015 & 64.34630 & 11 & 296 & -88 & 87 & -87 & 3.6 & 160 & 11 & 151 & -64 & $7.2 / 7.2$ & $\mathrm{R}$ & $4.11 / \mathrm{Gi}$ \\
\hline FT16 & 291 & $280 / 5.1$ & -15 & 64.94 & -15 & 64.34 & 9 & 192 & -66 & 181 & -66 & 3.8 & 189 & 9 & 343 & -74 & $5 / 6.1$ & $\mathrm{R}$ & $4.12 / \mathrm{Gi}$ \\
\hline FT15 & 312 & $280 / 4.9$ & -15.19657 & 64.94840 & -15.92237 & 64.34446 & 10 & 170 & -81 & 147 & -78 & 2.5 & 387 & 10 & 102 & -76 & 4.4 & $\mathrm{R}$ & 4.13/Gi \\
\hline FT14 & 289 & $280 / 5.1$ & -15.19607 & 64.94833 & -15.92471 & 64.34168 & 9 & 174 & -79 & 153 & -77 & 2.2 & 554 & 9 & 89 & -78 & $3.8 / 4.1$ & $\mathrm{R}$ & $4.15 / \mathrm{Gi}$ \\
\hline FT13 & 268 & $280 / 5.2$ & -15.19570 & 64.94793 & -15.92737 & 64.33947 & 11 & 319 & -82 & 1 & -85 & 2.7 & 297 & 11 & 164 & -54 & $5.2 / 5.2$ & $\mathrm{R}$ & $4.16 / \mathrm{Gi}$ \\
\hline FT12 & 260 & $280 / 5.3$ & -15.19543 & 64.94790 & -15.92815 & 64.33799 & 9 & 239 & -67 & 229 & -71 & 3.9 & 175 & 9 & 252 & -65 & $5.9 / 6.8$ & $\mathrm{R}$ & $4.17 / \mathrm{Gi}$ \\
\hline FT11 & 253 & $280 / 5.3$ & -15.19525 & 64.94785 & -15.92970 & 64.33670 & 7 & 224 & -77 & 200 & -79 & 5.4 & 127 & 7 & 212 & -81 & $9.8 / 10.2$ & $\mathrm{R}$ & $4.18 / \mathrm{Gi}$ \\
\hline FT10 & 245 & $280 / 5.4$ & -15.19562 & 64.94785 & -15.93248 & 64.33522 & 9 & 230 & -73 & 213 & -76 & 4.7 & 123 & 9 & 242 & -76 & $7.9 / 8.6$ & $\mathrm{R}$ & $4.19 / \mathrm{Gi}$ \\
\hline FT9 & 237 & $280 / 5.4$ & -15.19522 & 64.94750 & -15.93326 & 64.33374 & 10 & 139 & -62 & 134 & -57 & 2.4 & 416 & 10 & 53 & -52 & $2.5 / 3.5$ & $\mathrm{R}$ & $4.20 / \mathrm{Gi}$ \\
\hline FT8 & 226 & $280 / 5.5$ & -15.19435 & 64.94765 & -15.93470 & 64.33171 & 10 & 355 & 67 & 343 & 65 & 2.9 & 287 & 10 & 201 & 71 & $3.8 / 4.6$ & $\mathrm{~N}$ & $4.21 / \mathrm{Gi}$ \\
\hline FTB7 & 222 & $280 / 5.5$ & -15.19442 & 64.94760 & -15.93559 & 64.33097 & 10 & 9 & 86 & 318 & 83 & 2.7 & 315 & 10 & 312 & 72 & $5.2 / 5.3$ & $\mathrm{~N}$ & $4.22 / \mathrm{Gi}$ \\
\hline FT6 & 206 & $280 / 5.7$ & -15.19355 & 64.94728 & -15.94092 & 64.32553 & 8 & 40 & 66 & 28 & 68 & 3.5 & 246 & 8 & 102 & 71 & $5 / 6$ & $\mathrm{~N}$ & $4.25 / \mathrm{Gi}$ \\
\hline FT4 & 170 & $280 / 5.9$ & -15.19263 & 64.94700 & -15.94614 & 64.32036 & 11 & 125 & 29 & 127 & 34 & 2.4 & 379 & 11 & 33 & 3 & $1.5 / 2.7$ & $\mathrm{~N}$ & $4.28 / \mathrm{Gi}$ \\
\hline FT3 & 161 & $280 / 6.0$ & -15.19243 & 64.94690 & -15.94714 & 64.31869 & 8 & 118 & 29 & 119 & 35 & 2.2 & 647 & 8 & 40 & 5 & $1.4 / 2.5$ & $\mathrm{~N}$ & $4.30 / \mathrm{Gi}$ \\
\hline FT2 & 145 & $280 / 6.1$ & -15.19108 & 64.94678 & -15.96000 & 64.30715 & 8 & 216 & -69 & 199 & -71 & 1.9 & 853 & 8 & 287 & -77 & $2.9 / 3.3$ & $\mathrm{R}$ & 4.38/Gi \\
\hline FT1 & 155 & $280 / 6.0$ & -15.18877 & 64.94647 & -15.95911 & 64.30523 & 10 & 310 & -86 & 53 & -87 & 3.2 & 234 & 10 & 154 & -60 & $6.3 / 6.3$ & $\mathrm{R}$ & $4.38 / \mathrm{Gi}$ \\
\hline FS31 & 462 & $280 / 5.0$ & -15.11593 & 64.98622 & -15.84759 & 64.37728 & 9 & 333 & -72 & 347 & -74 & 5.4 & 92 & 9 & 172 & -35 & $8.9 / 9.8$ & $\mathrm{R}$ & 4.16/Gi \\
\hline FS30 & 451 & $280 / 5.1$ & -15.11592 & 64.98593 & -15.85004 & 64.37525 & 9 & 250 & -78 & 231 & -82 & 2.8 & 332 & 9 & 201 & -70 & $5.4 / 5.5$ & $\mathrm{R}$ & $4.18 / \mathrm{Gi}$ \\
\hline FS29 & 435 & $280 / 5.1$ & -15.11575 & 64.98573 & -15.85359 & 64.37229 & 8 & 140 & -58 & 135 & -54 & 2.5 & 476 & 8 & 48 & -50 & $2.5 / 3.6$ & $\mathrm{R}$ & $4.20 / \mathrm{Gi}$ \\
\hline FS28 & 423 & $280 / 5.2$ & -15.11597 & 64.98520 & -15.85625 & 64.36908 & 10 & 329 & 77 & 316 & 73 & 3.3 & 213 & 10 & 259 & 69 & $5.3 / 5.9$ & $\mathrm{~N}$ & $4.21 / \mathrm{Gi}$ \\
\hline FS27 & 417 & $280 / 5.2$ & -15.11618 & 64.98498 & -15.85759 & 64.36797 & 9 & 54 & 73 & 38 & 77 & 1.9 & 752 & 9 & 57 & 74 & $3.2 / 3.5$ & $\mathrm{~N}$ & $4.22 / \mathrm{Gi}$ \\
\hline FS26 & 398 & $280 / 5.3$ & -15.11668 & 64.98400 & -15.86281 & 64.36346 & 6 & 70 & 68 & 62 & 72 & 9.6 & 50 & 6 & 59 & 60 & $14.9 / 16.9$ & $\mathrm{~N}$ & $4.24 / \mathrm{Gi}$ \\
\hline FS25 & 385 & $280 / 5.4$ & -15.11673 & 64.98347 & -15.86569 & 64.36005 & 10 & 115 & 42 & 116 & 47 & 2.9 & 283 & 10 & 39 & 15 & $2.4 / 3.7$ & $\mathrm{~N}$ & $4.26 / \mathrm{Gi}$ \\
\hline
\end{tabular}


Table 2. Continued

\begin{tabular}{|c|c|c|c|c|c|c|c|c|c|c|c|c|c|c|c|c|c|c|c|}
\hline Site & Elev & Azi/Dip & SLon & SLat & SLon & SLat & $N$ & $\mathrm{D}$ & 1 & $D^{\prime}$ & 1 & $\alpha 95$ & $\mathrm{k}$ & $\mathrm{R}$ & VLon & VLat & $\mathrm{d} p / \mathrm{d} m$ & Pol. & MAge \\
\hline FS24 & 364 & $280 / 5.5$ & -15.11562 & 64.98293 & -15.86936 & 64.35617 & 11 & 66 & 63 & 59 & 68 & 3.0 & 238 & 11 & 70 & 57 & $4.1 / 5$ & $\mathrm{~N}$ & $4.29 / \mathrm{Gi}$ \\
\hline FS23 & 350 & $280 / 5.6$ & -15.11527 & 64.98245 & -15.88511 & 64.34123 & 10 & 220 & -54 & 212 & -57 & 2.1 & 555 & 10 & 293 & -57 & $2.2 / 3$ & $\mathrm{R}$ & $4.38 / \mathrm{Gi}$ \\
\hline FS22 & 330 & $280 / 5.7$ & -15.11465 & 64.98237 & -15.88756 & 64.33920 & 11 & 245 & -57 & 239 & -61 & 1.7 & 736 & 11 & 259 & -50 & $2 / 2.6$ & $\mathrm{R}$ & $4.40 / \mathrm{Gi}$ \\
\hline FS21 & 320 & $280 / 5.8$ & -15.11430 & 64.98223 & -15.89011 & 64.33624 & 10 & 223 & -68 & 209 & -70 & 3.9 & 152 & 10 & 275 & -72 & $5.8 / 6.8$ & $\mathrm{R}$ & $4.42 / \mathrm{Gi}$ \\
\hline FS20 & 303 & $280 / 5.8$ & -15.11402 & 64.98193 & -15.96813 & 64.27133 & 10 & 340 & 77 & 323 & 73 & 2.6 & 342 & 10 & 255 & 72 & $4.2 / 4.7$ & $\mathrm{~N}$ & $4.86 / \mathrm{Gi}$ \\
\hline FS19 & 300 & $280 / 5.9$ & -15.11402 & 64.98192 & -15.99560 & 64.24847 & 10 & 218 & -82 & 176 & -82 & 2.6 & 344 & 10 & 158 & -79 & $5 / 5.1$ & $\mathrm{R}$ & $5.02 / \mathrm{Gi}$ \\
\hline FS18 & 294 & $280 / 5.9$ & -15.11358 & 64.98177 & -15.99760 & 64.24680 & 9 & 307 & -65 & 315 & -70 & 2.7 & 372 & 9 & 194 & -33 & $4 / 4.6$ & $\mathrm{R}$ & $5.03 / \mathrm{Gi}$ \\
\hline FS17 & 285 & $280 / 5.9$ & -15.11325 & 64.98162 & -15.99860 & 64.24514 & 10 & 177 & -67 & 164 & -65 & 3.3 & 210 & 10 & 19 & -71 & $4.4 / 5.4$ & $\mathrm{R}$ & $5.04 / \mathrm{Gi}$ \\
\hline FS16 & 276 & $280 / 6.0$ & -15.11323 & 64.98148 & -15.99971 & 64.24322 & 11 & 161 & -67 & 150 & -63 & 1.8 & 615 & 11 & 39 & -65 & $2.3 / 2.9$ & $\mathrm{R}$ & $5.04 / \mathrm{Gi}$ \\
\hline FS15 & 271 & $280 / 6.0$ & -15.11318 & 64.98137 & -16.00393 & 64.23971 & 9 & 159 & -60 & 151 & -56 & 3.4 & 225 & 9 & 30 & -58 & $3.6 / 5$ & $\mathrm{R}$ & $5.07 / \mathrm{Gi}$ \\
\hline FS14 & 252 & $280 / 6.1$ & -15.11277 & 64.98103 & -16.00637 & 64.23767 & 10 & 21 & 74 & 360 & 74 & 4.1 & 140 & 10 & 166 & 86 & $6.6 / 7.4$ & $\mathrm{~N}$ & $5.08 / \mathrm{Gi}$ \\
\hline FS13 & 241 & $280 / 6.2$ & -15.11258 & 64.98083 & -16.00815 & 64.23619 & 9 & 43 & 65 & 30 & 68 & 3.0 & 301 & 9 & 99 & 69 & $4.2 / 5$ & $\mathrm{~N}$ & $5.09 / \mathrm{Gi}$ \\
\hline FS12 & 233 & $280 / 6.2$ & -15.11237 & 64.98065 & -16.01270 & 64.23157 & 10 & 166 & 82 & 210 & 82 & 3.5 & 192 & 10 & 332 & 50 & $6.6 / 6.8$ & $\mathrm{~N}$ & $5.12 / \mathrm{Gi}$ \\
\hline FS11 & 208 & $280 / 6.4$ & -15.11157 & 64.98028 & -16.01604 & 64.22780 & 9 & 259 & 53 & 261 & 47 & 3.5 & 224 & 9 & 275 & 22 & $2.9 / 4.5$ & $\mathrm{~N}$ & $5.14 / \mathrm{Gi}$ \\
\hline $\mathrm{FS} 10$ & 193 & $280 / 6.4$ & -15.11122 & 64.98003 & -16.01681 & 64.22632 & 10 & 29 & 57 & 19 & 58 & 2.0 & 587 & 10 & 131 & 62 & $2.2 / 3$ & $\mathrm{~N}$ & $5.15 / \mathrm{Gi}$ \\
\hline FS9 & 185 & $280 / 6.5$ & -15.11115 & 64.97990 & -16.02103 & 64.22281 & 9 & 26 & 68 & 10 & 69 & 4.1 & 159 & 9 & 136 & 78 & $6 / 7$ & $\mathrm{~N}$ & $5.18 / \mathrm{Gi}$ \\
\hline FS8 & 166 & $280 / 6.6$ & -15.11098 & 64.97965 & -16.02281 & 64.22133 & 9 & 358 & 86 & 306 & 82 & 2.1 & 585 & 9 & 305 & 69 & $4 / 4.1$ & $\mathrm{~N}$ & $5.19 / \mathrm{Gi}$ \\
\hline FS7 & 157 & $280 / 6.6$ & -15.11043 & 64.97950 & -16.02248 & 64.22078 & 9 & 25 & 88 & 300 & 84 & 2.5 & 427 & 9 & 314 & 68 & $4.8 / 4.9$ & $\mathrm{~N}$ & $5.19 / \mathrm{Gi}$ \\
\hline FS6 & 156 & $280 / 6.6$ & -15.11067 & 64.97940 & -16.02525 & 64.21830 & 9 & 344 & 86 & 305 & 81 & 2.7 & 367 & 9 & 298 & 69 & $5 / 5.2$ & $\mathrm{~N}$ & $5.20 / \mathrm{Gi}$ \\
\hline FS5 & 147 & $280 / 6.7$ & -15.11072 & 64.97907 & -16.02992 & 64.21442 & 11 & 11 & 68 & 355 & 67 & 2.8 & 265 & 11 & 177 & 75 & $3.9 / 4.7$ & $\mathrm{~N}$ & $5.23 / \mathrm{Gi}$ \\
\hline FS4 & 124 & $280 / 6.8$ & -15.10990 & 64.97848 & -16.02980 & 64.21268 & 9 & 90 & 80 & 73 & 86 & 2.6 & 382 & 9 & 2 & 65 & $5.2 / 5.2$ & $\mathrm{~N}$ & $5.23 / \mathrm{Gi}$ \\
\hline FS3 & 123 & $280 / 6.8$ & -15.10968 & 64.97827 & -16.03314 & 64.20991 & 10 & 34 & 70 & 15 & 72 & 1.8 & 710 & 10 & 111 & 80 & $2.8 / 3.2$ & $\mathrm{~N}$ & $5.25 / \mathrm{Gi}$ \\
\hline FS2 & 107 & $280 / 6.9$ & -15.10910 & 64.97797 & -16.03680 & 64.20603 & 9 & 62 & 71 & 45 & 76 & 2.1 & 592 & 9 & 56 & 71 & $3.6 / 3.9$ & $\mathrm{~N}$ & $5.28 / \mathrm{Gi}$ \\
\hline FS1 & 86 & $280 / 7.0$ & -15.10843 & 64.97767 & -16.03802 & 64.20418 & 9 & 356 & 75 & 335 & 72 & 3.5 & 223 & 9 & 234 & 76 & $5.3 / 6.1$ & $\mathrm{~N}$ & $5.29 / \mathrm{Gi}$ \\
\hline FR28 & 411 & $280 / 6.0$ & -15.01633 & 65.01493 & -15.94380 & 64.24303 & 11 & 49 & 71 & 32 & 74 & 4.4 & 107 & 11 & 73 & 75 & $7.3 / 8$ & $\mathrm{~N}$ & $5.28 / \mathrm{Gi}$ \\
\hline FR27 & 393 & $280 / 6.1$ & -15.01642 & 65.01475 & -15.94780 & 64.23970 & 11 & 1 & 69 & 347 & 67 & 2.9 & 253 & 11 & 197 & 74 & $4 / 4.8$ & $\mathrm{~N}$ & $5.30 / \mathrm{Gi}$ \\
\hline FR26 & 378 & $280 / 6.2$ & -15.01565 & 65.01463 & -15.95113 & 64.23693 & 9 & 337 & -88 & 81 & -85 & 3.1 & 279 & 9 & 142 & -61 & $6 / 6.1$ & $\mathrm{R}$ & $5.32 / \mathrm{Gi}$ \\
\hline FR25 & 364 & $280 / 6.3$ & -15.01562 & 65.01423 & -15.95424 & 64.23334 & 10 & 154 & -85 & 123 & -80 & 3.6 & 179 & 10 & 117 & -68 & $6.7 / 7$ & $\mathrm{R}$ & $5.34 / \mathrm{Mi}$ \\
\hline FR24 & 353 & $280 / 6.3$ & -15.01570 & 65.01387 & -15.95668 & 64.23131 & 10 & 237 & -78 & 208 & -81 & 2.8 & 300 & 10 & 201 & -77 & $5.2 / 5.4$ & $\mathrm{R}$ & $5.35 / \mathrm{Mi}$ \\
\hline FR23 & 335 & $280 / 6.4$ & -15.01507 & 65.01383 & -15.95901 & 64.22854 & 14 & 345 & -58 & 355 & -61 & 5.1 & 62 & 14 & 168 & -16 & $5.9 / 7.8$ & $\mathrm{R}$ & 5.37/Mi \\
\hline FR22 & 338 & $280 / 6.4$ & -15.01562 & 65.01328 & -15.96090 & 64.22680 & 10 & 230 & -76 & 204 & -79 & 2.8 & 307 & 10 & 219 & -79 & $5 / 5.2$ & $\mathrm{R}$ & $5.38 / \mathrm{Mi}$ \\
\hline FR21 & 315 & $280 / 6.6$ & -15.01535 & 65.01332 & -15.96412 & 64.22329 & 11 & 215 & -74 & 191 & -76 & 2.6 & 311 & 11 & 262 & -85 & $4.4 / 4.8$ & $\mathrm{R}$ & $5.40 / \mathrm{Mi}$ \\
\hline FR20 & 308 & $280 / 6.6$ & -15.01495 & 65.01303 & -15.96568 & 64.22199 & 10 & 260 & -72 & 249 & -78 & 2.4 & 425 & 10 & 216 & -63 & $4.2 / 4.4$ & $\mathrm{R}$ & $5.41 / \mathrm{Mi}$ \\
\hline FR19 & 304 & $280 / 6.6$ & -15.01348 & 65.01337 & -15.96457 & 64.22126 & 11 & 240 & -69 & 225 & -74 & 3.4 & 184 & 11 & 245 & -69 & $5.5 / 6.1$ & $\mathrm{R}$ & $5.41 / \mathrm{Mi}$ \\
\hline FR18 & 286 & $280 / 6.7$ & -15.01428 & 65.01285 & -15.96956 & 64.21793 & 7 & 237 & -75 & 212 & -79 & 2.6 & 545 & 7 & 218 & -77 & $4.7 / 4.9$ & $\mathrm{R}$ & $5.44 / \mathrm{Mi}$ \\
\hline FR17 & 258 & $280 / 6.9$ & -15.01415 & 65.01265 & -15.97578 & 64.21275 & 11 & 244 & -55 & 237 & -60 & 1.9 & 557 & 11 & 261 & -50 & $2.2 / 2.9$ & $\mathrm{R}$ & $5.47 / \mathrm{Mi}$ \\
\hline FR16 & 255 & $280 / 6.9$ & -15.01162 & 65.01287 & -16.10920 & 64.10008 & 10 & 29 & -81 & 59 & -77 & 2.3 & 443 & 10 & 133 & -46 & $4 / 4.3$ & $\mathrm{R}$ & 6.24/Mi \\
\hline FR15 & 235 & $280 / 7.0$ & -15.01177 & 65.01267 & -16.11142 & 64.09823 & 9 & 24 & -83 & 63 & -79 & 2.8 & 346 & 9 & 134 & -50 & $5 / 5.3$ & $\mathrm{R}$ & $6.25 / \mathrm{Mi}$ \\
\hline FR14 & 222 & $280 / 7.1$ & -15.01103 & 65.01263 & -16.11331 & 64.09583 & 9 & 239 & -73 & 217 & -78 & 3.3 & 240 & 9 & 229 & -75 & $5.9 / 6.2$ & $\mathrm{R}$ & $6.27 / \mathrm{Mi}$ \\
\hline FR13 & 193 & $280 / 7.3$ & -15.01037 & 65.01250 & -16.11675 & 64.09213 & 10 & 229 & -69 & 210 & -73 & 3.2 & 227 & 10 & 261 & -75 & $5.1 / 5.7$ & $\mathrm{R}$ & 6.30/Mi \\
\hline FR12 & 186 & $280 / 7.3$ & -15.00977 & 65.01173 & -16.18158 & 64.03719 & 9 & 16 & 66 & 360 & 66 & 3.1 & 279 & 9 & 165 & 74 & $4.1 / 5$ & $\mathrm{~N}$ & 6.67/Mi \\
\hline FR11 & 181 & $280 / 7.3$ & -15.01005 & 65.01152 & -16.18270 & 64.03627 & 11 & 236 & 49 & 241 & 43 & 5.5 & 70 & 11 & 290 & 11 & $4.2 / 6.8$ & $\mathrm{~N}$ & 6.67/Mi \\
\hline FR10 & 171 & $280 / 7.4$ & -15.01017 & 65.01087 & -16.18492 & 64.03342 & 8 & 252 & 72 & 260 & 65 & 6.1 & 229 & 4 & 286 & 37 & 8/9.8 & $\mathrm{N}$ & 6.68/Mi \\
\hline FR9 & 144 & $280 / 7.6$ & -15.01000 & 65.01058 & -16.19091 & 64.02843 & 7 & 1 & 83 & 318 & 79 & 8.9 & 47 & 7 & 289 & 73 & $16.1 / 16.9$ & $\mathrm{~N}$ & $6.72 / \mathrm{Mi}$ \\
\hline FR8 & 144 & $280 / 7.6$ & -15.01010 & 65.01037 & -16.19136 & 64.02706 & 9 & 37 & 80 & 354 & 80 & 3.5 & 216 & 9 & 328 & 83 & $6.5 / 6.7$ & $\mathrm{~N}$ & $6.72 / \mathrm{Mi}$ \\
\hline FR7 & 130 & $280 / 7.6$ & -15.00968 & 65.01008 & -16.19402 & 64.02484 & 8 & 18 & 71 & 356 & 71 & 3.1 & 330 & 8 & 180 & 81 & $4.6 / 5.3$ & $\mathrm{~N}$ & $6.74 / \mathrm{Mi}$ \\
\hline FR6 & 99 & $280 / 7.8$ & -15.00962 & 65.00942 & -16.20091 & 64.01811 & 6 & 38 & 77 & 2 & 79 & 3.2 & 442 & 6 & 352 & 86 & $5.7 / 6$ & $\mathrm{~N}$ & $6.78 / \mathrm{Mi}$ \\
\hline FR5 & 97 & $280 / 7.8$ & -15.00683 & 65.01015 & -16.19880 & 64.01837 & 7 & 63 & 73 & 40 & 79 & 3.0 & 396 & 7 & 43 & 74 & $5.4 / 5.7$ & $\mathrm{~N}$ & 6.78/Mi \\
\hline FR4 & 68 & $280 / 8.0$ & -15.00688 & 65.00922 & -16.23819 & 63.98460 & 8 & 218 & -65 & 200 & -68 & 4.9 & 129 & 8 & 295 & -73 & $6.9 / 8.2$ & $\mathrm{R}$ & 7.00/Mi \\
\hline
\end{tabular}

is the circle of 95 per cent confidence (Fisher 1953). Of the 123 sites, 62 sites are of normal polarity and 61 sites are of reverse polarity. Based on common mean tests (Tauxe 1998), direct field observations and the new radiometric ages (Table 1), we found that only 113 sites are statistically distinct (of the sites that apparently recorded the same snapshot of the field, we simply discarded one of those sites for the further analysis; see Table 2 for information about sites excluded for further analysis). Hence, there exists some stratigraphic overlap between the investigated sections; see Fig. 2. In addition, we mapped 12 potential transitional polarity sites with $-45^{\circ}<\mathrm{VGP}_{\text {latitude }}<45^{\circ}$. Seven of these sites have normal polarity and five have reverse polarity (Table 2 ).

Sections FR to FV were drilled by Watkins \& Walker (1977) who sampled two cores per site. A review of the polarity mapping of Watkins \& Walker (1977) shows that there's a high correlation with the polarity distributions found in this study, with only a few major exceptions. Watkins \& Walker (1977) suggest, for example, the presence of a reverse polarity near site FV7 and FV8, while this is not observed in this study (Table 2). In section FT, Watkins \& Walker (1977) mapped to FT32/FT33 (positive polarity), while additional flows were mapped in this study and revealed the evidence of a short reverse polarity interval at FT35, followed by normal polarities. When looking into detail, however, a marked difference is found between mapped declination and inclination values for positively correlated flows (see Supporting Information Fig. S2-1). Notably, the differences show a Gaussian distribution, indicating that they relate to higher levels of random noise in the data set of Watkins \& Walker (1977) as compared to the new data set. Thus, some of the observed differences may relate to sun versus magnetic bearings (96 per cent of all cores in the new data set were oriented using a sun compass), while other differences may relate to the fact that Watkins \& Walker (1977) collected only two cores per site.

For the following analysis we excluded the 12 potential transitional sites as defined by a VGP latitude cut-off of $\pm 45^{\circ}$ (see Section 5). We further excluded two sites with $k=46.9$ and $k=$ 49.9. This cut-off is based on results by Supakulopas (2018) on Icelandic lavas, showing that the estimated VGP dispersion of a suite becomes stable around a certain mean for $k>\sim 80$, with a marked drop in change between $k>\sim 60$ and $k>\sim 80$. The resulting 46 normal and 53 reverse site mean directions are defined by $N \geq 5$ and $\alpha 95 \leq 6$. As shown in Supporting Information Fig. S2-2 shown to be Fisherian, the hypothesis that the distribution of directions is Fisherian cannot be rejected at a 5 per cent significance level. The 46 normal sites yield a mean direction of declination $\left(D_{\text {normal }}\right)=0.1^{\circ}$ and inclination $\left(I_{\text {normal }}\right)=77.5^{\circ}\left(\alpha 95=3.0^{\circ}\right)$, while the 53 reverse sites yield a mean direction of declination $\left(D_{\text {reverse }}\right)=190.4^{\circ}$ and 

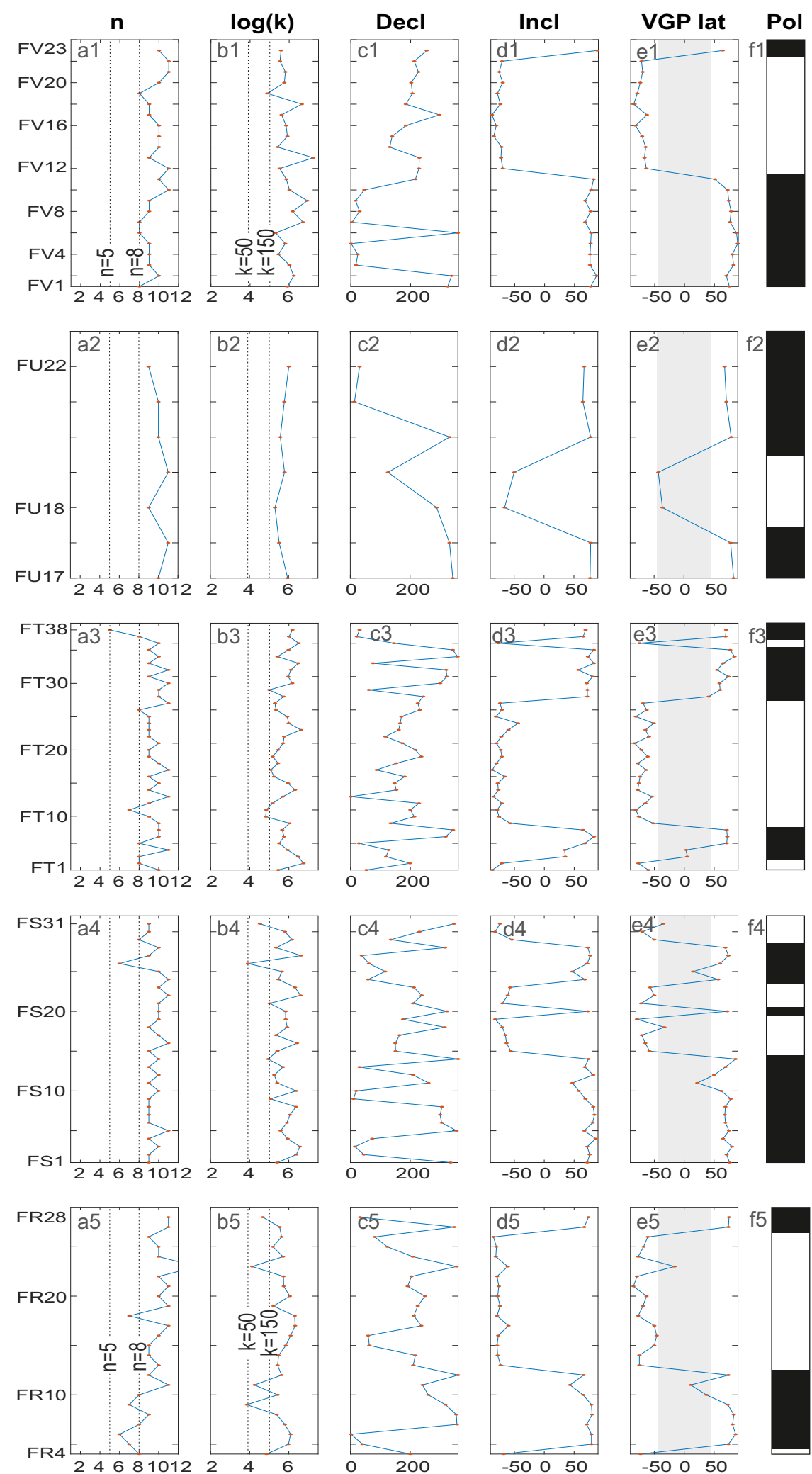

Figure 6. Summary plots of information provided in Table 2 for sections FR (top panels) to FV (bottom panels). Columns: (a) Number of independent directions, ChRM (n); (b) log of Fisher precision parameter $k$; (c) declination $\left(^{\circ}\right)$; (d) Inclination $\left(^{\circ}\right)$; (e) VGP latitude $\left(^{\circ}\right.$ ); (f) polarity. For reference, the vertical lines in Column (a) are for $n=4$ and $n=8$, while the vertical lines in (b) are for $k=50$ and $k=150$. The grey bar in Column (e) highlights VGP latitudes between $-45^{\circ}$ and $45^{\circ}$. 

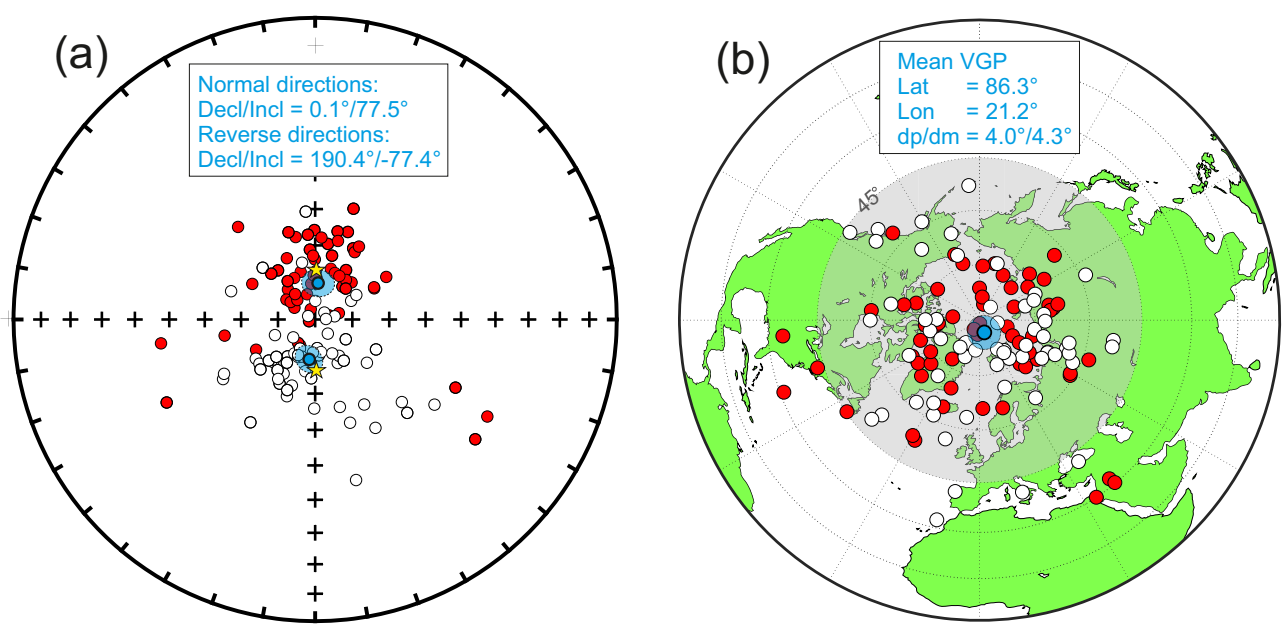

Figure 7. (a) Equal area projection of Fljótsdalur site mean palaeodirections corrected for post-emplacement tectonic movements. Filled and open circles plot on the lower and upper hemisphere, respectively. Grand mean directions (filled blue circles) with $\alpha 95$ confidence ellipses (transparent blue) calculated for sites that fulfill quality criteria (see Table 3). Yellow stars: Expected directions from a GAD field. (b) VGP positions. Transparent grey circle is at $45^{\circ}$ latitude. Filled (open) circles are northern hemisphere (antipodes of southern hemisphere) VGP positions. Filled blue circles: Grand mean VGP (palaeomagnetic pole) and 95 per cent confidence ellipses calculated for sites that fulfill quality criteria (see Table 3). As shown in (b) the resulting mean palaeomagnetic pole coincides with the North Pole within the 95 per cent confidence limits.

Table 3. Palaeodirectional mean statistics for selected 99 sites that fulfill the quality criteria (see the text). $N$, total number independent units; D/I, Grand mean declination $\left({ }^{\circ}\right) /$ inclination $\left({ }^{\circ}\right) ; \alpha 95\left(^{\circ}\right)$, Fisher $(1953)$ circle of $95 \%$ confidence; $k$, Estimate of the Fisher (1953) precision parameter. $\operatorname{VGP}_{\text {lat }} / \mathrm{VGP}_{\text {lon }}$ : Grand mean VGP latitude $\left({ }^{\circ}\right)$ and longitude $\left({ }^{\circ}\right) . \mathrm{d} p / \mathrm{d} m: 95 \%$ confidence angles $\left({ }^{\circ}\right)$ in parallel and meridian.

\begin{tabular}{lcrrrrrrr}
\hline & $N$ & \multicolumn{1}{c}{$D$} & \multicolumn{1}{c}{$I$} & $\alpha 95$ & $k$ & $\mathrm{VGP}_{\text {lat }}$ & $\mathrm{VGP}_{\text {lon }}$ & $\mathrm{d} p / \mathrm{d} m$ \\
\hline Normal & 46 & 0.1 & 77.5 & 3.0 & 50 & 87.3 & -17.1 & $5.3 / 5.6$ \\
Reverse & 53 & 190.4 & -77.4 & 3.3 & 34 & -84.7 & 37.5 & $5.8 / 6.2$ \\
Combined & 99 & 5.6 & 77.5 & 2.3 & 41 & 86.3 & 21.2 & $4.0 / 4.3$ \\
\hline
\end{tabular}

inclination $\left(I_{\text {reverse }}\right)=-77.4^{\circ}\left(\alpha 95=3.3^{\circ}\right)$ (Table 3, Fig. 7b). The normal and reverse directions pass a bootstrap reversals test (Tauxe 2010) at the 95 per cent level of confidence (Supporting Information Fig. S2-4) and a Watson (1983) V-test (Supporting Information Fig. S2-5) support they have a common mean direction, indicating that the normal and reverse data can be combined. The 53 reverse directions were therefore inverted and an overall mean was calculated of the combined data set of $N=99$ with a result $\left(D=5.6^{\circ}\right.$, $\left.I=77.5^{\circ}, \alpha 95=2.3^{\circ}\right)$ that is not significantly different from that expected from a geocentric axial dipole field $\left(I_{\mathrm{GAD}}=76.5^{\circ}\right)$. The resulting palaeomagnetic pole position that would give rise to the site mean magnetic field direction under the assumption of a GAD field is shown in Fig. 7(d) and given by VGP latitude $_{\text {and }} \mathrm{VGP}_{\text {longitude }}$ of $86.3^{\circ} \mathrm{N}$ and $21.2^{\circ} \mathrm{E}$ with semi-axes of the ellipse of confidence $(\mathrm{dp} / \mathrm{dm})$ of 4.0/4.3. This result from the Fljótsdalur samples show that the North Pole is within the 95 percent confidence region of the palaeomagnetic pole.

\section{DISCUSSION}

\subsection{Chronostratigraphic age model of Fljótsdalur}

In order to analyse the PSV for specific time intervals, we need a solid age model for sections FR to FV. We have built a new composite chronostratigraphic age model based on field observations (Fig. 2), ${ }^{40} \mathrm{Ar} /{ }^{39} \mathrm{Ar}$ results (Table 1), palaeodirectional data (Table 2) and resultant intersection stratigraphic correlations. The age model provides a time constraint on our subsequent PSV analysis of the palaeodirectional data.

In Fig. 8(a), we plot the 17 new ${ }^{40} \mathrm{Ar} /{ }^{39} \mathrm{Ar}$ radiometric ages against the cumulative stratigraphic height $(\mathrm{CSH})$ for the dated lava flows in sections FR to FV. We estimated the CSH using the approach of Døssing et al. (2016) from Jökuldalur, that is, by considering the stratigraphic thickness of each lava flow and taking into account the tectonic tilt (Table 2) and the relative age chronology of the sections (Fig. 2). Fig. 8(a) indicates that the 17 new ${ }^{40} \mathrm{Ar} /{ }^{39} \mathrm{Ar}$ ages define an overall linear trend with $\mathrm{CSH}$, thus supporting the conclusion of Watkins \& Walker (1977); McDougall et al. (1977) that the volcanic build-up rate in eastern Iceland can be assumed to have remained overall constant for interhiatus intervals on timescales of $10^{5}-10^{6}$ years. We therefore assumed a segmented linear regression age model as a valid first order approximation to model the ${ }^{40} \mathrm{Ar} /{ }^{39} \mathrm{Ar}$ ages versus CSH. First, we calculated a linear regression model for the long age interval defined by sites FR17 (CSH $\sim 190 \mathrm{~m}$ ) to site FS19 (CSH $\sim 570 \mathrm{~m}$ ) (Fig. 2, Table 2). This interval contains three new ${ }^{40} \mathrm{Ar} /{ }^{39} \mathrm{Ar}$ ages and is bounded above and below by major hiatuses. We used the FR17-FS19 linear regression model as an approximation to the remaining age intervals using the assumption of overall constant build-up rates between major hiatuses. However, for the relatively young and short interval defined by sites FV12FV22, which was formed during the first glaciations and contains several hiati (Fig. 2), we calculated a separate - and less steepregression model to fit the ${ }^{40} \mathrm{Ar}{ }^{39} \mathrm{Ar}$ age of FV21 and the GTS2012 polarity timescale of Gradstein et al. (2012) (see below). The result is shown in Fig. 8(b). In order to assign ages to all sites along the sections, we used the age-versus-CSH regression model together with the $\mathrm{CSH}$ for all sites to calculate the interpolated model age for each site (Fig. 8c). Finally, we used these model ages to correlate and fit with the polarity intervals of GTS2012 (Gradstein et al. 2012) in order to obtain a complete chronstratigraphic age model for Fljótsdalur (Fig. 8d). All model ages are listed in Table 2.

The new age model for sections FR to FV in Fljótsdalur shows that the sections (excluding site FV23 in top of section FV) span the age interval 2.08-7.0 Ma, covering eight normal polarity intervals and ten reverse polarity intervals. The uppermost site, FV23, has a 
(a)

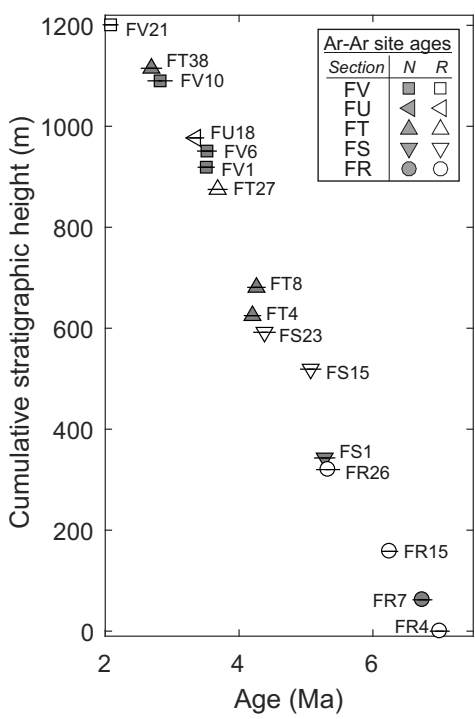

(b)

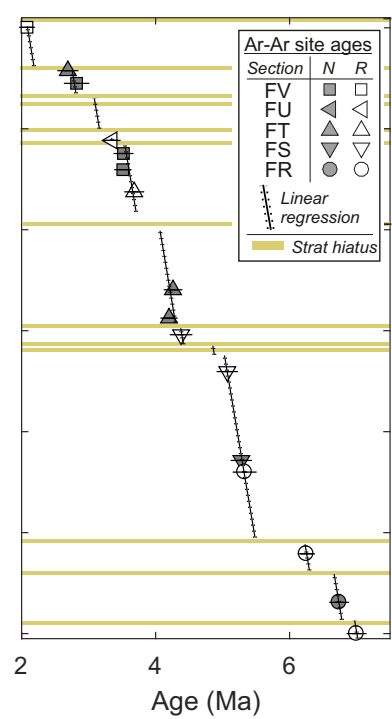

(c)

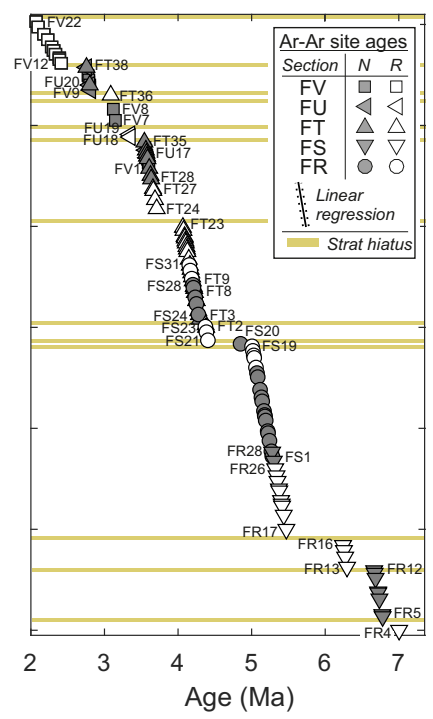

(d)

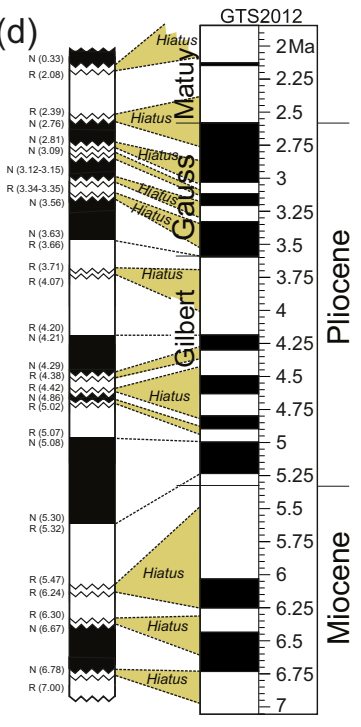

Figure 8. (a) ${ }^{40} \mathrm{Ar} /{ }^{39} \mathrm{Ar}$ ages versus cumulative stratigraphic height (CSH) for sections FR- FV. (b) First-order segmented regression model based on the ${ }^{40} \mathrm{Ar} /{ }^{39} \mathrm{Ar}$ data. Also shown are major hiatuses in the stratigraphic column as determined from field observations (Fig. 2) and ${ }^{40} \mathrm{Ar} /{ }^{39} \mathrm{Ar}$ data (Table 1$)$. (c) Interpolated model ages for all sites according to their CSH. Black (white) symbols are normal (reverse) polarity. (d) Revised magneto-chronostratigraphic age model based on correlation to GTS2012 (Gradstein et al. 2012).

radiometric age of $0.33 \pm 0.01 \mathrm{Ma}$ and a normal polarity (Tables 1 and 2), indicating that it belongs to Brunhes. Hence, a significant hiatus of 1.75 Myr (0.33-2.08 Ma) exists in the top of Section FV. Additional significant hiatuses in the stratigraphic record are found at the base of site FV12 (2.18-2.78 Ma), at the base of site FS21 (4.41-4.86 Ma) and at the base of site FR17 (5.47-6.24 Ma) (Fig. 2). Although numerous smaller hiatuses are interpreted throughout the sections, the new age model for Fljótsdalur indicate that the 113 distinct flows are well distributed over an age interval of $2.08 \mathrm{Ma}$ to $7.00 \mathrm{Ma}$ (Fig. 8d).

\subsection{PSV analysis: 1-7 Ma}

A key objective of GAD studies is to estimate TAF and PSV for well-dated time intervals using modern-standard high-quality data (Johnson et al. 2008; Cromwell et al. 2018). It is also of particular interest to compare normal and reverse polarity intervals, such as the Brunhes and Matuyama chrons, which have repeatedly been shown to record significantly different overall geomagnetic field behaviours (Merrill \& McElhinny 1977; Johnson et al. 2008; Ziegler et al. 2011; Vişan et al. 2016; Cromwell et al. 2018). However, global palaeomagnetic databases are dominated by results from Brunhes as well as low- to mid-latitudes, whereas data from the older chrons, including the Matuyama, Gauss and Gilbert chrons, as well as from high latitudes, are relatively scarce (Johnson et al. 2008; Cromwell et al. 2018). Only Lawrence et al. (2009) published a large data set for high southerly latitudes that spans the last $7 \mathrm{Myr}$.

Døssing et al. (2016) published modern-standard $\left(N_{\text {mean }}>10\right.$ and $k_{\text {mean }}>200$ ) palaeodirectional results from 45 individual lava flows with well-constrained ${ }^{40} \mathrm{Ar} /{ }^{39} \mathrm{Ar}$ ages from Jökuldalur (see Fig. 1 for location). Of the 45 lava flows from Jökuldalur, only a single flow is of Brunhes age $(0.63 \pm 0.03 \mathrm{Ma})$ while the remaining 44 flows span an age interval of 1.01-3.13 Ma. Eleven of these flows are older than $2 \mathrm{Ma}$ and, hence, have a temporal overlap with the $>2.08$ Ma flows in sections FR to FV in Fljótsdalur. The temporal spread of the combined Jökuldalur and Fljótsdalur palaeodirectional data is plotted in Fig. 9. As shown, the Jökuldalur data cluster mainly in the Matuyama reverse polarity chron (1.00-2.59 Ma), whereas the Fljótsdalur data cluster in the Gauss normal and Gilbert reverse polarity chrons $(2.59-5.32 \mathrm{Ma})$ as well as in the late Miocene. Looking at one Myr intervals, the combined data set comprise two directions from 0-1 Ma, 31 directions from 1-2 Ma, 28 directions from 2-3 Ma, 19 directions from 3-4 Ma, 28 directions from 4-5 $\mathrm{Ma}, 26$ directions from 5-6 Ma, and 9 directions from 6-7 Ma, that is, only the $0-1 \mathrm{Ma}$ and 6-7 Ma intervals are particularly poorly constrained by data.

For the following analysis of PSV, we combine the palaeodirectional results from Fljótsdalur and Jökudalur. We exclude the two Brunhes data points as well as two data points with $k \leq 50$. The site statistics for the combined palaeodirections (Supporting Information Fig. S2-6) show that the palaeodirections provide a high-quality comprehensive data set that is suitable for PSV analysis for the 1-7 Ma interval for high northern latitudes.

The summary statistic used to characterize PSV is the dispersion of the site mean directions through time, which can be evaluated quantitatively using VGPs from each distinct site. We use the modified angular standard deviation for the dispersion $S_{B}$ (Johnson et al. 2008), the root-mean-square angular deviation of VGPs about the geographic axis:

$S_{B}=\sqrt{\frac{1}{N-1} \sum_{i=1}^{N}\left(\Delta_{i}^{2}-\frac{S_{w_{i}}^{2}}{N_{s_{i}}}\right)}$

$\Delta_{i}$ represents the angular deviation of the pole for the $i$ th site from the geographic north pole, $N$ is the number of sites, and $\mathrm{S}_{B}$ represents the geomagnetic signal remaining after correcting for the within-site dispersion $S_{w_{i}}$ determined from $N_{S_{i}}$ samples.

We calculate and compare the dispersion $S_{B}$ specifically for the Matuyama $\left(S_{B(\text { Mat })}\right)$, Gauss $\left(S_{B(\text { Gauss })}\right)$ and Gilbert $\left(S_{B(\text { Gil })}\right)$ chrons in order to map any differences in PSV between these geomagnetic intervals such as has been suggested for the Brunhes normal and Matuyama reverse intervals (Johnson et al. 2008; Vişan et al. 2016; 


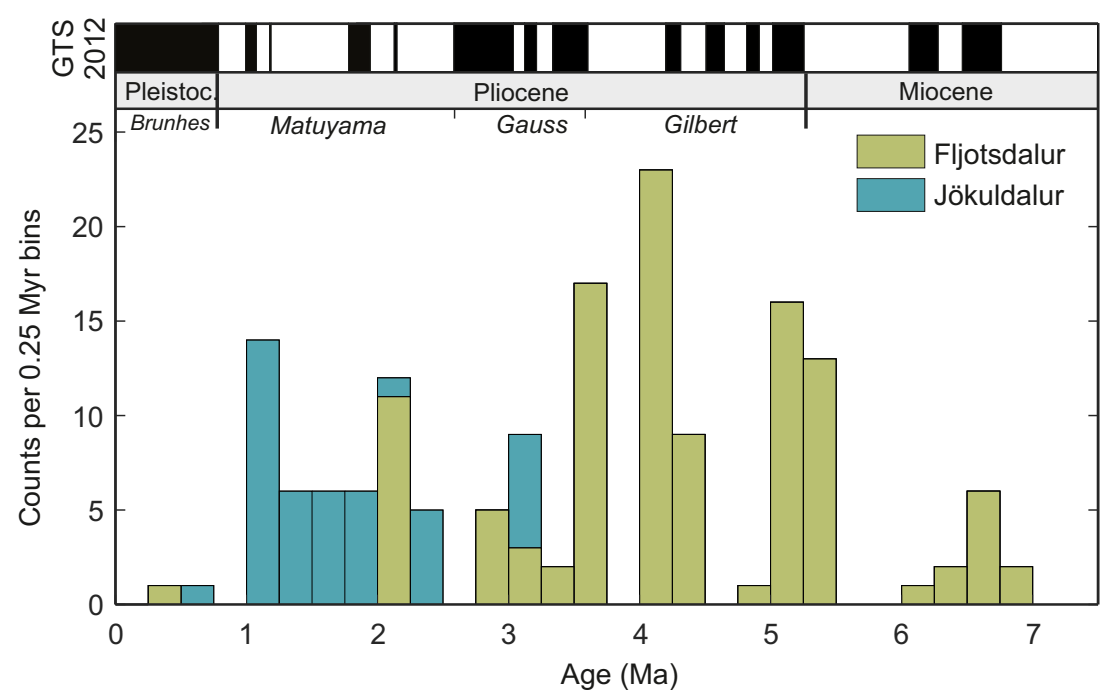

Figure 9. Histogram plot of number of independent site mean directions as a function of model ages for Fljótsdalur data (this study) and Jökuldalur data (Døssing et al. 2016). The data have been binned in $0.25 \mathrm{Myr}$ intervals.

Cromwell et al. 2018). We further calculate the dispersion for all data combined $\left(S_{B(1-7)}\right)$ as well as separately for all normal polarity data only $\left(S_{B(1-7(N))}\right)$ and for all reverse polarity data only $\left(S_{B(1-7(R))}\right)$. Transitional data are often defined as measurements with an absolute value of VGP latitude less than $45^{\circ}$ (Johnson et al. 2008) or less than an empirically defined latitude (Vandamme 1994). Based on these latitude cut-off criteria, VGP dispersion values are typically presented for all data (i.e. including low latitude VGPs) as well as for 'non-transitional' VGPs only (Johnson et al. 2008; Lawrence et al. 2009). However, as argued by Kristjansson (2013) VGPs from Iceland show a smooth and continuous frequency distribution in latitude, suggesting that secular variation, excursions and transitions could be treated jointly in VGP statistical studies. This observation is partly supported by the distribution of VGPs in this study, which shows that less than 7 percent of VGP latitudes fall below $45^{\circ}$ and that the distribution is relatively smooth (see Supporting Information Fig. S2-7). However, for comparison purposes, we present dispersion results without latitude cut-off as well as for $\pm 45^{\circ}$ and Vandamme (1994) cut-offs. The calculated VGP dispersion results are listed in Table 4.

If no VGP cut-off is applied to the entire 1-7 Ma data set, we observe a higher dispersion for normal polarity VGPs $\left(30.3 \frac{37.1}{23.4}\right)$ as compared to the reverse polarity VGPs $\left(25.0 \frac{28.1}{22.0}\right)$ although the two estimates of VGP dispersion are not statistically distinguishable. This result potentially contradicts other studies of a somewhat higher VGP dispersion during reverse polarity intervals (Merrill \& McElhinny 1977; Johnson et al. 2008). However, it may simply relate to the fact that very-low-latitude VGPs in Fljótsdalur are predominantly observed for normal polarity data and, hence, the data play a (too) significant role when estimating the dispersion without cut-off. If applying a VGP cut-off, we find for the 1-7 Ma data set that the dispersion for normal polarity VGPs becomes $19.7 \frac{22.1}{17.4}$ and $19.7 \frac{21.9}{17.3}$ for $\mathrm{a} \pm 45^{\circ}$ and a Vandamme (1994) cut-off, respectively. For the reverse data, the corresponding values become $22.0 \frac{23.8}{19.9}$ and $22.0 \frac{24.0}{20.0}$, that is, although the upper and lower bounds of the 1-7 Ma VGP dispersion for the normal and reverse VGPs overlap, these results tend to support previous conclusions of a somewhat higher VGP dispersion during reverse polarity intervals (Johnson et al. 2008; Cromwell et al. 2018).
When comparing individual chrons, we find that the VGP dispersion for the Matuyama reverse chron $\left(S_{B(\text { Mat })}=19.8 \frac{21.7}{17.8}\right)$ is solely directly comparable to the dispersion for the Gauss normal chron $\left(S_{B(\text { Gauss })}=20.4 \frac{24.2}{15.7}\right)$ if applying the $\pm 45^{\circ}$ cut-off, whereas markedly higher dispersion values are found for the Gauss chron regardless of using no cut-off or the Vandamme (1994) cut-off. It is evident, however, that the high dispersion for the Gauss data could be related to the limited number of data points (20-23) as compared to the Matuyama (54-55). However, recalculating the mean VGP dispersion for 1000 randomly selected subsets of 23 data points of the Matuyama data results in $S_{B(\text { Mat 23) }}=19.7 \frac{22.7}{16.6}, S_{B(\text { Mat 23) }}=19.7 \frac{22.8}{16.6}$ and $S_{B(\text { Mat 23) }}=19.3 \frac{21.9}{16.5}$, respectively, for no cut-off, a $\pm 45^{\circ}$ cut-off and a Vandamme (1994) latitude cut-off of $\pm 49.5^{\circ}$. Thus, it appears that a higher dispersion - according to our data - may have characterized the Gauss chron. Interestingly, we find that the mean VGP dispersion for the Matuyama data (regardless of VGP cut-off) is smaller than the mean VGP dispersion found in Brunhes-age rocks from Jan Mayen at $71^{\circ} \mathrm{N}$ north of Iceland (Cromwell et al. 2013), even when accounting for a $\sim 1.3^{\circ}$ (Model G; Doubrovine et al. 2019 ) or $\sim 0.4^{\circ}$ (Model TK03; Tauxe \& Kent 2004) increase in dispersion from $64^{\circ} \mathrm{N}$ (northern Iceland) to $71^{\circ} \mathrm{N}$ (Jan Mayen). Our results may therefore contradict former conclusions (Johnson et al. 2008) of a more stable field during the Brunhes.

For the Gilbert reverse chron data, we find that the VGP dispersion, regardless of VGP cut-off, is generally higher than for the Gauss and Matuyama chrons. This may reflect real geomagnetic field behaviour with a more variable field during the Gilbert period. A similar tendency was observed by Kristjansson (2013).

Numerical models (Hatakeyama \& Kono 2002) and field observations (Johnson et al. 2008) show that the dispersion in VGP positions is expected to vary according to latitude, with a general tendency to increase towards the poles. Several PSV models have been parametrized in terms of expected latitudinal variations in such observations (Johnson et al. 2008; Johnson \& McFadden 2015). In Fig. 10, we compare our VGP dispersion results (Table 4) against the two most commonly discussed types of models, Model G of McFadden et al. (1988) and the TK03 model of Tauxe \& Kent (2004), which are based on PSV from recent lavas. We use the revised versions of Model G (Doubrovine et al. 2019) for the 0-5 Ma and 0-10 
Table 4. VGP dispersion for Fljótsdalur \& Jökuldalur data sets combined.

\begin{tabular}{lccccccc}
\hline Name & Age interval & Polarity & VGP latitude cut-off & $\mathrm{n}$ & $S_{\text {mean }}$ & $\frac{S_{\text {upper }}}{S_{\text {lower }}}$ & Site mean latitude \\
\hline$S_{B(1-7)}$ & $1-7 \mathrm{Ma}$ & $\mathrm{N} / \mathrm{R}$ & - & 154 & 27.2 & $\frac{30.3}{23.9}$ & $64.6^{\circ} \mathrm{N}$ \\
$S_{B(1-7)}$ & $1-7 \mathrm{Ma}$ & $\mathrm{N} / \mathrm{R}$ & $\operatorname{Van}\left(> \pm 47^{\circ}\right)$ & 142 & 21.1 & $\frac{22.6}{19.5}$ & $64.6^{\circ} \mathrm{N}$ \\
$S_{B(1-7)}$ & $1-7 \mathrm{Ma}$ & $\mathrm{N} / \mathrm{R}$ & $> \pm 45^{\circ}$ & 142 & 21.1 & $\frac{22.5}{19.5}$ & $64.4^{\circ} \mathrm{N}$ \\
$S_{B(1-7(N))}$ & $1-7 \mathrm{Ma}$ & $\mathrm{N}$ & - & 61 & 30.3 & $\frac{37.1}{23.4}$ & $64.4^{\circ} \mathrm{N}$ \\
$S_{B(1-7(N))}$ & $1-7 \mathrm{Ma}$ & $\mathrm{N}$ & Van $\left(> \pm 49.6^{\circ}\right)$ & 54 & 19.7 & $\frac{22.9}{17.3}$ & $64.4^{\circ} \mathrm{N}$ \\
$S_{B(1-7(N))}$ & $1-7 \mathrm{Ma}$ & $\mathrm{N}$ & $> \pm 45^{\circ}$ & 54 & 19.7 & $\frac{22.1}{17.4}$ & $64.5^{\circ} \mathrm{N}$ \\
$S_{B(1-7(R))}$ & $1-7 \mathrm{Ma}$ & $\mathrm{R}$ & - & 93 & 25.0 & $\frac{28.1}{22.0}$ & $64.7^{\circ} \mathrm{N}$ \\
$S_{B(1-7(R))}$ & $1-7 \mathrm{Ma}$ & $\mathrm{R}$ & Van $\left(> \pm 45.4^{\circ}\right)$ & 88 & 22.0 & $\frac{24.0}{20.0}$ & $64.7^{\circ} \mathrm{N}$ \\
$S_{B(1-7(R))}$ & $1-7 \mathrm{Ma}$ & $\mathrm{R}$ & $> \pm 45^{\circ}$ & 88 & 22.0 & $\frac{23.8}{19.9}$ & $64.7^{\circ} \mathrm{N}$ \\
$S_{B(\text { Mat) }}$ & Matuyama & $\mathrm{N} / \mathrm{R}$ & - & 55 & 19.8 & $\frac{21.7}{17.8}$ & $65.0^{\circ} \mathrm{N}$ \\
$S_{B(\text { Mat })}$ & Matuyama & $\mathrm{N} / \mathrm{R}$ & Van $\left(> \pm 51.1^{\circ}\right)$ & 54 & 19.1 & $\frac{20.6}{17.3}$ & $65.0^{\circ} \mathrm{N}$ \\
$S_{B(\text { Mat })}$ & Matuyama & $\mathrm{N} / \mathrm{R}$ & $> \pm 45^{\circ}$ & 55 & 19.8 & $\frac{21.8}{17.7}$ & $65.0^{\circ} \mathrm{N}$ \\
$S_{B(\text { Gauss })}$ & Gauss & $\mathrm{N} / \mathrm{R}$ & - & 23 & 25.9 & $\frac{32.3}{19.5}$ & $64.4^{\circ} \mathrm{N}$ \\
$S_{B(\text { Gauss })}$ & Gauss & $\mathrm{N} / \mathrm{R}$ & Van $\left(> \pm 42.0^{\circ}\right)$ & 22 & 23.9 & $\frac{29.1}{18.2}$ & $64.4^{\circ} \mathrm{N}$ \\
$S_{B(\text { Gauss })}$ & Gauss & $\mathrm{N} / \mathrm{R}$ & $> \pm 45^{\circ}$ & 20 & 20.4 & $\frac{24.2}{15.7}$ & $64.4^{\circ} \mathrm{N}$ \\
$S_{B(\text { Gil })}$ & Gilbert & $\mathrm{N} / \mathrm{R}$ & - & 65 & 31.5 & $\frac{37.3}{26.1}$ & $64.3^{\circ} \mathrm{N}$ \\
$S_{B(\text { Gil })}$ & Gilbert & $\mathrm{N} / \mathrm{R}$ & Van $\left(> \pm 43.2^{\circ}\right)$ & 58 & 23.2 & $\frac{25.5}{20.4}$ & $64.3^{\circ} \mathrm{N}$ \\
$S_{B(\text { Gil })}$ & Gilbert & $\mathrm{N} / \mathrm{R}$ & $> \pm 45^{\circ}$ & 58 & 23.2 & $\frac{25.6}{20.8}$ & $64.3^{\circ} \mathrm{N}$ \\
\hline
\end{tabular}

Notes: n, number of independent sites. $S_{\text {mean }} \frac{S_{\text {upper }}}{S_{\text {Swer }}}$, mean dispersion with $95 \%$ bootstrapped upper and lower confidence levels (Tauxe 2010). Van, latitude cut-off using the Vandamme (1994) criteria.

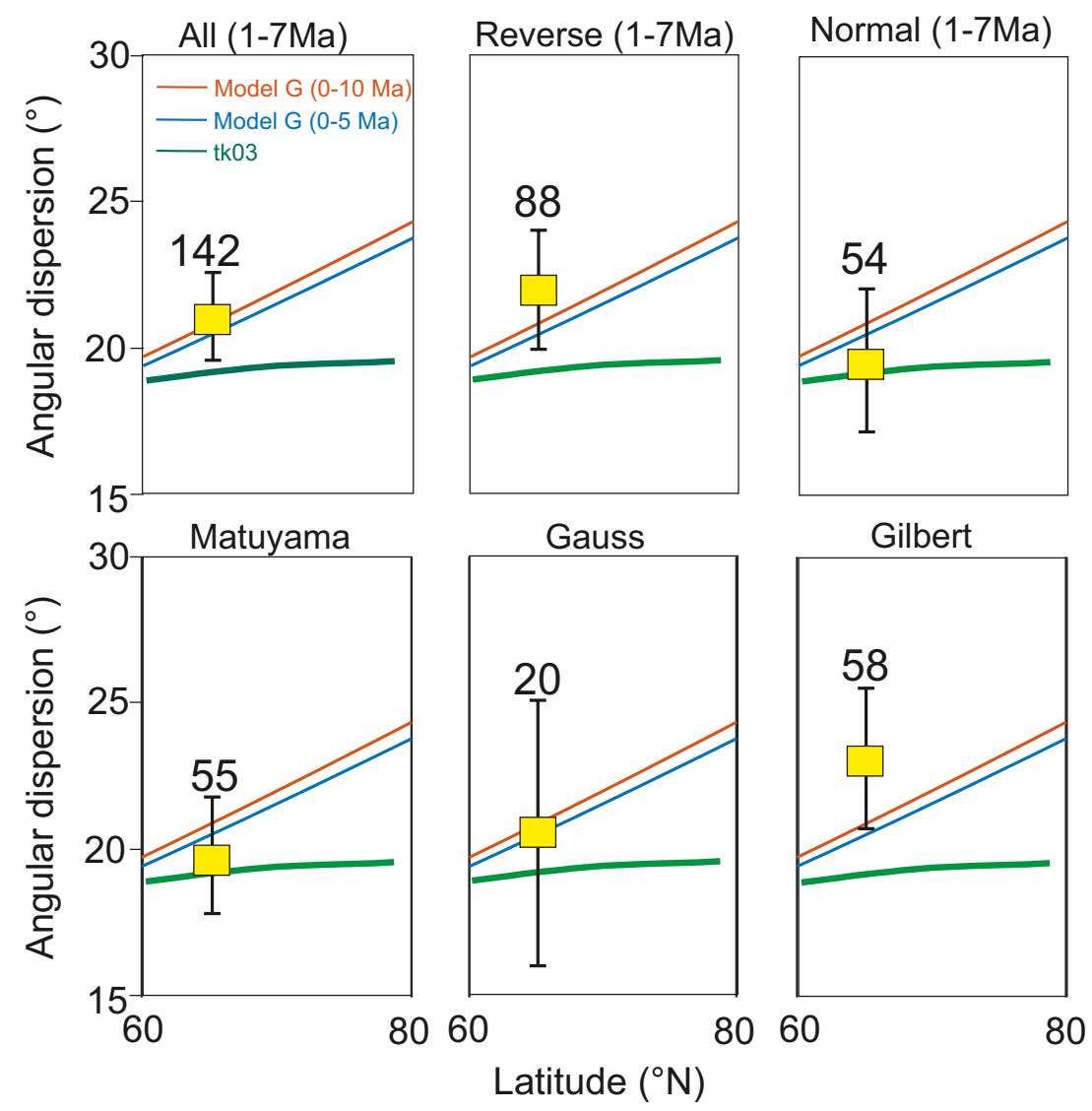

Figure 10. VGP dispersion data for the Fljótsdalur and Jökuldalur palaeodirections using a VGP latitude cut-off of $45^{\circ}$. Upper panels: $1-7$ Ma data sets. Lower panels: Matuyama, Gauss and Gilbert polarity chrons. All dispersion values are calculated from data sets with the quality selection criteria $k>50$ and $N>5$. Data are shown with bootstrapped 95 per cent levels of confidence error bars. Blue/red lines: revised Model G curves for 0-5 Ma and 0-10 Ma data compilations, respectively (Doubrovine et al. 2019). Green line: TK03 (Tauxe \& Kent 2004). 
Ma intervals based on the recent compilations of (Opdyke et al. 2015) and Cromwell et al. (2018).

It is clear from Fig. 10 that neither Model G nor TK03 fits the dispersion data consistently. Using all data (top panels in Fig. 10), the data tend to fit the Model $\mathrm{G}$ best, except for the 1-7 Ma normal polarity data $\left(S_{B(1-7(N))}\right)$, which is closer to TK03. Only minor difference is observed for Model $\mathrm{G}$ when comparing the 0-5 Ma and $0-10 \mathrm{Ma}$ intervals, which (as also noted by Doubrovine et al. (2019)) possibly relates to the fact that most of the data of Cromwell et al. (2018) fall within the $0-5 \mathrm{Ma}$ interval. A very nice fit is obtained for all data combined $S_{B(1-7)}$ to Model G, whereas $S_{B(1-7)}$ is not fitted by TK03, even when considering the uncertainty of $S_{B(1-7)}$.

When considering the individual chrons represented by the data set (bottom panels in Fig. 10), we find likewise an inconsistent fit to the two models. While the Matuyama data appear to be closer to $\mathrm{TK} 03$, the normal polarity Gauss chron is closer to Model G (although the Gauss angular dispersion is less well constrained due to only 20 data points), and the reverse Gilbert chron data is significantly higher than even the Model G prediction. Considering the uncertainties of the $S_{b}$ values, all estimates, except that for the Gilbert subset, are consistent with Model G, while the discrepancy with TK03 is generally larger.

\section{CONCLUSIONS}

In this paper, we present new high-quality palaeodirectional data based on $\sim 1300$ cores from 123 accepted sites along five sections in the Fljótsdalur valley in eastern Iceland, at about $65^{\circ} \mathrm{N}$. The sites are dominantly found to be of late Miocene to late Pliocene age (2.08-7.00 Ma) based on 17 new high-resolution incremental heating ${ }^{40} \mathrm{Ar} /{ }^{39} \mathrm{Ar}$ age determinations. Only one site is of Brunhes age.

Due to excellent weather conditions during the field campaigns, 96 per cent of all cores were oriented using both a Brunton compass and a sun compass, thus providing us with a unique data set for comparing magnetic and sun azimuths at high northern latitudes. We find that 42, 16 and 3 per cent of the magnetic azimuth estimates (corrected to true north) deviate more than $\pm 5^{\circ}, \pm 10^{\circ}$ and $\pm 20^{\circ}$, respectively, from the corresponding sun azimuth estimates. This suggest that core sampling intended for high-quality PSV studies at high northern latitudes should preferably be oriented by sun (or alternatively by a differential GPS).

Based on AF- and thermal-demagnetization experiments, we obtain well-grouped ChRM directions from 113 distinct sites $\left(N_{\text {mean }}=\right.$ $\left.9.5, k_{\text {mean }}=353, \alpha 95_{\text {mean }}=3.1^{\circ}\right)$. It is shown that the mean direction of the data is consistent with the direction of the GAD field and the mean palaeomagnetic pole is not significantly different from the present axis of rotation.

By setting strict quality criteria $(N>5, k>50)$ and combining the Fljótsdalur data with overall 1-2.5 Ma data from Jökuldalur (Døssing et al. 2016), we obtain a high-quality data set with 154 independent site mean directions for PSV analysis for the 1-7 Ma time interval. We use these data to calculate dispersion of VGPs and find indications of a higher VGP dispersion during reverse polarity intervals than during normal polarity intervals. We compare individual polarity chrons and find that a higher dispersion tends to be observed for the Gilbert reverse polarity chron as compared to the Gauss and Matuyama chrons. We further compare our results against Brunhes age VGP dispersion data obtained from Jan Mayen (Cromwell et al. 2013) and find no evidence of a higher VGP scatter during the Matuyama as has previously been suggested (Johnson et al. 2008).

Importantly, the VGP scatter data $S_{b}$ presented in this study are generally not well-fitted by the two commonly used models for VGP dispersion: Model G and TK03. However, considering the uncertainties of the $S_{b}$ values, all estimates, except that for the Gilbert subset, are consistent with Model G, while the Discrepancy with TK03 is generally larger. A very nice fit is obtained for all data combined to Model G, whereas $S_{B(1-7)}$ is not fitted by TK03, even when considering the uncertainty of $S_{B(1-7)}$.

All data presented in this study and by Døssing et al. (2016) will be made available to the MagIC database.

\section{ACKNOWLEDGEMENTS}

We are grateful to Prof. V. Bachtadse, Drs P. Riisager, J. Matzka and L. Kristjansson for providing drilling equipment and assisting with field work planning. Thanks to Oli Shorttle, Lucy Tweed and Will Miller (former students at Cambridge University) who were in the field to assist with the drilling. Thanks also to Manesh Mistry (former student at Oxford University) for demagnetization of multiple samples as part of his M.Sc. project. Finally, we thank Pavel V. Doubrovine, Elisa Piispa, Lisa Tauxe and Andy Biggin for constructive reviews. AD was funded by the Danish Council for Independent Research (12-125623). MSR was funded by the Icelandic Centre for Research (09021002).

\section{REFERENCES}

Argus, D.F., Gordon, R.G. \& DeMets, C., 2011. Geologically current motion of 56 plates relative to the no-net-rotation reference frame, Geochem. Geophys. Geosyst., 12(11), doi:10.1029/2011GC003751.

Aubert, J., Tarduno, J.A. \& Johnson, C.L., 2010. Observations and models of the long-term evolution of Earth's magnetic field, Space Sci. Rev., 155(1-4), 337-370.

Camps, P., Singer, B., Carvallo, C., Goguitchaichvili, A., Fanjat, G. \& Allen, B., 2011. The Kamikatsura event and the Matuyama-Brunhes reversal recorded in lavas from Tjörnes Peninsula, northern Iceland, Earth planet. Sci. Lett., 310(1), 33-44.

Cromwell, G., Tauxe, L., Staudigel, H., Constable, C., Koppers, A. \& Pedersen, R.-B., 2013. In search of long-term hemispheric asymmetry in the geomagnetic field: results from high northern latitudes, Geochem. Geophys. Geosyst., 14(8), 3234-3249.

Cromwell, G., Johnson, C., Tauxe, L., Constable, C. \& Jarboe, N., 2018. Psv10: a global data set for 0-10 Ma time-averaged field and paleosecular variation studies, Geochem. Geophys. Geosyst., 19, 1533-1558

Dagley, P. et al., 1967. Geomagnetic polarity zones for Icelandic lavas, Nature, 216(5110), 25-29.

Døssing, A., Muxworthy, A.R., Supakulopas, R., Riishuus, M.S. \& Mac Niocaill, C., 2016. High northern geomagnetic field behavior and new constraints on the Gilsá event: Paleomagnetic and 40Ar/39Ar results of 0.5-3.1 ma basalts from Jökuldalur, Iceland, Earth planet. Sci. Lett., 456, 98-111.

Doubrovine, P.V., Veikkolainen, T., Pesonen, L.J., Piispa, E., Ots, S., Smirnov, A.V., Kulakov, E.V. \& Biggin, A.J., 2019. Latitude dependence of geomagnetic paleosecular variation and its relation to the frequency of magnetic reversals: Observations from the cretaceous and jurassic, Geochem. Geophys. Geosyst., 20(3), 1240-1279.

Fisher, R., 1953. Dispersion on a sphere, Proc. R. Soc. A, 217(1130), 295305.

Gradstein, F., Ogg, J., Schmitz, M. \& Ogg, G., 2012. The Geologic Time Scale 2012, Vol. 2, Elsevier.

Gudmundsson, A., 1978. The geology of Muli and its surroundings, National Energy Authority of Iceland, Report OS-ROD 7818, 50 pp. 
Hardarson, B., Fitton, J., Ellam, R. \& Pringle, M., 1997. Rift relocation: a geochemical and geochronological investigation of a palaeo-rift in northwest Iceland, Earth planet. Sci. Lett., 153(3-4), 181-196.

Hatakeyama, T. \& Kono, M., 2002. Geomagnetic field model for the last 5 my: time-averaged field and secular variation, Phys. Earth planet. Inter., 133(1-4), 181-215.

Hospers, J., 1954. Rock magnetism and polar wandering, Nature, 173, $1183-$ 1184.

Jicha, B.R., Kristjánsson, L., Brown, M.C., Singer, B.S., Beard, B.L. \& Johnson, C.M., 2011. New age for the Skálamælifell excursion and identification of a global geomagnetic event in the late Brunhes chron, Earth planet. Sci. Lett., 310(3), 509-517.

Johnson, C. \& Constable, C., 1997. The time-averaged geomagnetic field: global and regional biases for 0-5 Ma, Geophys. J. Int., 131(3), 643-666.

Johnson, C. \& McFadden, P., 2007. Time-averaged field and paleosecular variation, in Treatise on Geophysics, pp. 417-453, ed. Schubert, G., Elsevier.

Johnson, C. \& McFadden, P., 2015. 5.11-The time-averaged field and paleosecular variation, in Treatise on Geophysics, 2nd edn, pp. 385-417, ed. Schubert, G., Elsevier.

Johnson, C. et al., 2008. Recent investigations of the 0-5 ma geomagnetic field recorded by lava flows, Geochem. Geophys. Geosyst., 9(4), doi:10.1029/2007GC001696.

Kirschvink, J.L., 1980. The least-squares line and plane and the analysis of palaeomagnetic data, Geophys. J. Int., 62(3), 699-718.

Koppers, A.A., 2002. ArArCALC-software for 40 Ar/39 Ar age calculations, Comput. Geosci., 28(5), 605-619.

Koppers, A.A., Staudigel, H. \& Duncan, R.A., 2003. High-resolution 40Ar/39Ar dating of the oldest oceanic basement basalts in the western pacific basin, Geochem. Geophys. Geosyst., 4(11), doi:10.1029/2003GC000574.

Korte, M., Constable, C., Donadini, F. \& Holme, R., 2011. Reconstructing the Holocene geomagnetic field, Earth planet. Sci. Lett., 312(3), 497-505.

Kristjánsson, L., 2008. Paleomagnetic research on Icelandic lava flows, Jökull, 58, 101-116.

Kristjansson, L., 2013. Analyses of primary remanence vector data from a large collection of lava flows: towards improved methodology in paleogeomagnetism, Stud. Geophys. Geod., 57(4), 543-564.

Kristjánsson, L. \& Jóhannesson, H., 1999. Secular variation and reversals in a composite $2.5 \mathrm{~km}$ thick lava section in central Western Iceland, Earth Planets Space, 51(4), 261-276.

Kristjánsson, L. \& Jonsson, G., 2007. Paleomagnetism and magnetic anomalies in Iceland, J. Geodyn., 43(1), 30-54.

Kuiper, K., Deino, A., Hilgen, F., Krijgsman, W., Renne, P. \& Wijbrans, J., 2008. Synchronizing rock clocks of Earth history, Science, 320(5875), $500-504$.

Lawrence, K., Tauxe, L., Staudigel, H., Constable, C., Koppers, A., McIntosh, W. \& Johnson, C., 2009. Paleomagnetic field properties at high southern latitude, Geochem. Geophys. Geosyst., 10(1), doi: $10.1029 / 2008 \mathrm{GC} 002072$.

Lhuillier, F. \& Gilder, S.A., 2013. Quantifying paleosecular variation: insights from numerical dynamo simulations, Earth planet. Sci. Lett., 382, 87-97.

Linder, J. \& Leonhardt, R., 2009. Paleomagnetic full vector record of four consecutive Mid Miocene geomagnetic reversals, Phys. Earth planet. Inter, 177(1-2), 88-101.

Lurcock, P.C. \& Wilson, G.S., 2012. Puffinplot: a versatile, user-friendly program for paleomagnetic analysis, Geochem. Geophys. Geosyst., 13(Q06Z45), doi:10.1029/2012GC004098.

McDougall, I., Saemundsson, K., Johannesson, H., Watkins, N. \& Kristjansson, L., 1977. Extension of the geomagnetic polarity time scale to 6.5 my: K-Ar dating, geological and paleomagnetic study of a 3,500-m lava succession in western Iceland, Bull. geol. Soc. Am., 88(1), 1-15.

McFadden, P., Merrill, R. \& McElhinny, M., 1988. Dipole/quadrupole family modeling of paleosecular variation, J. geophys. Res., 93(B10), $11583-$ 11588 .
Merrill, R.T. \& McElhinny, M.W., 1977. Anomalies in the time-averaged paleomagnetic field and their implications for the lower mantle, Rev. Geophys., 15(3), 309-323.

Min, K., Mundil, R., Renne, P.R. \& Ludwig, K.R., 2000. A test for systematic errors in $40 \mathrm{Ar} / 39 \mathrm{Ar}$ geochronology through comparison with $\mathrm{U} / \mathrm{Pb}$ analysis of a 1.1-Ga rhyolite, Geochim. Cosmochim. Acta, 64(1), 73-98.

Mussett, A., Ross, J. \& Gibson, I., 1980. 40Ar/39Ar dates of eastern Iceland lavas, Geophys. J. R. astr. Soc., 60(1), 37-52.

Opdyke, N., Kent, D.V., Foster, D. \& Huang, K., 2015. Paleomagnetism of Miocene volcanics on Sao Tome: Paleosecular variation at the equator and a comparison to its latitudinal dependence over the last $5 \mathrm{Myr}$, Geochem. Geophys. Geosyst., 16(11), 3870-3882.

Pálmason, G. \& Sæmundsson, K., 1974. Iceland in relation to the MidAtlantic Ridge, Annu. Rev. Earth Planet. Sci., 2(1), 25-50.

Pavón-Carrasco, F.J., Osete, M.L., Torta, J.M. \& De Santis, A., 2014. A geomagnetic field model for the Holocene based on archaeomagnetic and lava flow data, Earth planet. Sci. Lett., 388, 98-109.

Ross, J. \& Mussett, A., 1976. 40Ar/39Ar dates for spreading rates in eastern Iceland, Nature, 259(5538), 36.

Steiger, R. \& Jäger, E., 1977. Subcommission on geochronology: convention on the use of decay constants in geo-and cosmochronology, Earth planet. Sci. Lett., 36(3), 359-362.

Supakulopas, R., 2018. Deviations from the geocentric axial dipole hypothesis: high-latitude study of the palaeomagnetic field, PhD thesis, unpublished $\mathrm{PhD}$ thesis, Imperial College London (Natural Magnetism Group).

Tauxe, L., 1998. Paleomagnetic Principles and Practice, Springer.

Tauxe, L., 2010. Essentials of Paleomagnetism, University of California Press.

Tauxe, L. \& Kent, D.V., 2004. A simplified statistical model for the geomagnetic field and the detection of shallow bias in paleomagnetic inclinations: was the ancient magnetic field dipolar?, Timescales of the Paleomagnetic Field, Geophysical Monograph Series, Vol. 145, pp. 101-115, eds Channell, J.E.T., Kent, D.V., Lowrie, W. \& Meert, J.G., AGU.

Taylor, J., 1997. Introduction to Error Analysis: the Study of Uncertainties in Physical Measurements, University Science Books.

Vandamme, D., 1994. A new method to determine paleosecular variation, Phys. Earth planet. Inter, 85(1), 131-142.

Vişan, M., Panaiotu, C.G., Necula, C. \& Dumitru, A., 2016. Palaeomagnetism of the Upper Miocene-Lower Pliocene lavas from the East Carpathians: contribution to the paleosecular variation of geomagnetic field, Sci. Rep., 6, 23411.

Watkins, N. \& Walker, G., 1977. Magnetostratigraphy of eastern Iceland, Am. J. Sci., 277(5), 513-584.

Watson, G.S., 1983. Statistics on Spheres, John Wiley \& Sons .

York, D., 1968. Least squares fitting of a straight line with correlated errors, Earth planet. Sci. Lett., 5, 320-324.

Ziegler, L. \& Constable, C., 2015. Testing the geocentric axial dipole hypothesis using regional paleomagnetic intensity records from 0 to $300 \mathrm{ka}$, Earth planet. Sci. Lett., 423, 48-56.

Ziegler, L., Constable, C., Johnson, C. \& Tauxe, L., 2011. PADM2M: a penalized maximum likelihood model of the 0-2 Ma palaeomagnetic axial dipole moment, Geophys. J. Int., 184(3), 1069-1089.

\section{SUPPORTING INFORMATION}

Supplementary data are available at $G J I$ online.

\section{GAD_Paper2_FINAL_Supplmentary.pdf}

Please note: Oxford University Press is not responsible for the content or functionality of any supporting materials supplied by the authors. Any queries (other than missing material) should be directed to the corresponding author for the paper. 